\title{
Calculation and Experimental Measurement of Paramagnetic NMR Parameters of Phenolic Oximate Cu(II) Complexes
}

\author{
Daniel M. Dawson, Zhipeng Ke, Frederick M. Mack, Rachel A. Doyle, \\ Giulia P. M. Bignami, Iain A. Smellie, Michael Bühl and Sharon E. Ashbrook
}

School of Chemistry, EaStCHEM and Centre for Magnetic Resonance, University of St Andrews, North Haugh, St Andrews KY16 9ST, UK

Supporting Information

S1. Synthesis and Basic Characterisation of Oximes and $\mathrm{Cu}(\mathrm{II})$ Complexes

S2. Computational Details

S3. Solid-State NMR Details

S4. One- and Two-Dimensional Solid-State NMR Spectra of 2-5 and 7-9.

S5. Final Assignments of ${ }^{1} \mathrm{H}$ and ${ }^{13} \mathrm{C}$ NMR Spectra of 2-5 and 7-9.

S6. Vibrational Effects on the pNMR Parameters of 1

S7. References 


\section{S1. Synthesis and Basic Characterisation of Oximes and $\mathrm{Cu}(\mathrm{II})$ Complexes}

\section{Synthesis of the oximes}

All oxime ligands (denoted HLN, using the numbering scheme of the main text) were prepared using the same general protocol. The commercially-available starting aldehyde or ketone $(15 \mathrm{mmol})$ was dissolved in $80 \%$ aqueous ethanol $\left(40 \mathrm{~cm}^{3}\right)$. This was mixed with sodium acetate $(37 \mathrm{mmol})$ and hydroxylamine hydrochloride $(30 \mathrm{mmol})$ was dissolved in water $\left(10 \mathrm{~cm}^{3}\right)$ and then heated under reflux for $3 \mathrm{~h}$. The solvent was removed in vacuo and water $\left(20 \mathrm{~cm}^{3}\right)$ was added to the crude residue. The product was extracted using ethyl acetate $\left(3 \times 20 \mathrm{~cm}^{3}\right)$ and the three organic fractions were combined and washed with brine $\left(3 \times 15 \mathrm{~cm}^{3}\right)$. The organic layers were dried over anhydrous sodium sulfate and the solvent was removed in vacuo. The crude product was recrystallized from boiling 60-80 petroleum ether $\left(20 \mathrm{~cm}^{3}\right)$, with the addition of small portions of ethyl acetate if required.

As previously reported, ${ }^{\mathrm{S1}} \mathrm{HL1}$ was obtained in 52\% yield (mp. 56.2-58.3 ${ }^{\circ} \mathrm{C}$ lit. 56.1-58.1 $\left.{ }^{\circ} \mathrm{C}^{\mathrm{S} 2}\right) .{ }^{1} \mathrm{H}$ NMR: $\delta \mathrm{H}\left(400.13 \mathrm{MHz}, \mathrm{CDCl}_{3}, \mathrm{Me}_{4} \mathrm{Si}\right): 9.79(1 \mathrm{H}, \mathrm{s}, \mathrm{C}-\mathrm{OH}), 8.24(1 \mathrm{H}, \mathrm{t}, \mathrm{J}=0.4 \mathrm{~Hz}$, H7), 7.30 (1H, s, N-OH), 7.29 (1H, ddd, J = 8.3, 7.3, 1.7 Hz, H5), 7.19 (1H, ddt, J = 7.7, 1.7, $0.4 \mathrm{~Hz}, \mathrm{H3}), 6.99$ (1H, ddt, J = 8.3, 1.2, $0.4 \mathrm{~Hz}, \mathrm{H6}), 6.93$ (1H, ddd, J = 7.5, 7.4, $1.2 \mathrm{~Hz}, \mathrm{H} 4)$. ${ }^{13} \mathrm{C}\left\{{ }^{1} \mathrm{H}\right\} \mathrm{NMR}: \delta \mathrm{C}\left(100.66 \mathrm{MHz}, \mathrm{CDCl}_{3}, \mathrm{Me}_{4} \mathrm{Si}\right): 157.3$ (C1), 153.2 (C7), 131.5 (C5), 130.9 (C3), 119.9 (C4), 116.9 (C6) and $116.4(\mathrm{C} 2)$.

HL2 was obtained in $37 \%$ yield (mp. $117.7-120.0{ }^{\circ} \mathrm{C}$ lit. $\left.112{ }^{\circ} \mathrm{C}^{\mathrm{S}}\right) .{ }^{1} \mathrm{H}$ NMR: $\delta \mathrm{H}(400.13$ $\left.\mathrm{MHz}, \mathrm{CDCl}_{3}, \mathrm{Me}_{4} \mathrm{Si}\right) 11.49$ (1H, s, C-OH), 7.81 (1H, br s, N-OH), 7.45 (1H, ddd, J = 8.0, 1.6, $0.3 \mathrm{~Hz}, \mathrm{H6}), 7.28$ (1H, ddd, J = 8.2, 7.3, 1.6 Hz, H4), 6.99 (1H, ddd, J = 8.2, 1.3, $0.3 \mathrm{~Hz}, \mathrm{H3})$, $6.92(1 \mathrm{H}, \mathrm{ddd}, \mathrm{J}=8.0,7.3,1.3 \mathrm{~Hz}, \mathrm{H} 5), 2.37(3 \mathrm{H}, \mathrm{s}, \mathrm{H} 8) .{ }^{13} \mathrm{C}\left\{{ }^{1} \mathrm{H}\right\} \mathrm{NMR}: \delta \mathrm{C}\left(75.5 \mathrm{MHz}, \mathrm{CDCl}_{3}\right.$, $\mathrm{Me}_{4} \mathrm{Si}$ ) 159.6 (C7), 157.5 (C1), 130.9 (C6), 127.8 (C4), 119.5 (C3), 118.7 (C1), 117.4 (C5), 10.9 (C8).

HL3 was obtained in $43 \%$ yield (mp. $156.1-160.1{ }^{\circ} \mathrm{C}$ lit. $148.0-150.0{ }^{\circ} \mathrm{C}^{54}$ ). ${ }^{1} \mathrm{H}$ NMR: $\delta \mathrm{H}$ (400.13 MHz, CDCl, $\left.\mathrm{Me}_{4} \mathrm{Si}\right) 10.86$ (1H, s, C-OH), $9.15(1 \mathrm{H}, \mathrm{t}, \mathrm{J}=0.5 \mathrm{~Hz}, \mathrm{H} 7), 7.97$ (1H, dm, J 
$=8.5 \mathrm{~Hz}, \mathrm{ArH}), 7.80(1 \mathrm{H}, \mathrm{dm}, \mathrm{J}=9.0 \mathrm{~Hz}, \mathrm{ArH}), 7.79(1 \mathrm{H}, \mathrm{dm}, \mathrm{J}=8.1 \mathrm{~Hz}), 7.53(1 \mathrm{H}, \mathrm{ddd}, \mathrm{J}=$ 8.5, 6.9, $1.4 \mathrm{~Hz}, \mathrm{ArH}), 7.38$ (1H, ddd, J = 8.0, 6.9, $1.1 \mathrm{~Hz}, \mathrm{ArH}), 7.32$ (1H, br s, N-OH), 7.22 $(1 \mathrm{H}, \mathrm{dm}, \mathrm{J}=9.0 \mathrm{~Hz}, \mathrm{ArH}) .{ }^{13} \mathrm{C}\left\{{ }^{1} \mathrm{H}\right\} \mathrm{NMR}: \delta \mathrm{C}\left(75.5 \mathrm{MHz}, \mathrm{CDCl}_{3}, \mathrm{Me}_{4} \mathrm{Si}\right) 157.4(\mathrm{C} 2), 149.9$ (C7), $132.6(\mathrm{CH}), 131.9(\mathrm{C} 5 / 6), 129.0(\mathrm{CH}), 128.3$ (C5/6), $127.5(\mathrm{CH}), 123.6(\mathrm{CH}), 120.2(\mathrm{CH})$, $118.8(\mathrm{CH}), 106.8(\mathrm{C} 1)$.

HL4 was obtained in 56\% yield (mp. $120.0-121.4{ }^{\circ} \mathrm{C}$ lit. $\left.121{ }^{\circ} \mathrm{C}^{\mathrm{S} 5}\right) .{ }^{1} \mathrm{H}$ NMR: $\delta \mathrm{H}(400.13$ $\left.\mathrm{MHz}, \mathrm{CDCl}_{3}, \mathrm{Me}_{4} \mathrm{Si}\right) 10.0$ (1H, s(br), C-OH), 8.23 (1H, s, N-OH), 6.93-6.81 (3H, m, H4+5+6), $3.90(3 \mathrm{H}, \mathrm{s}, \mathrm{H} 8) .{ }^{13} \mathrm{C}\left\{{ }^{1} \mathrm{H}\right\} \mathrm{NMR}$ : $\delta \mathrm{C}\left(75.5 \mathrm{MHz}, \mathrm{CDCl}_{3}, \mathrm{Me}_{4} \mathrm{Si}\right) 152.6$ (C7), 148.2 (C2), 146.9 (C3), 122.4 (C4/6), 119.6 (C4/6), 116.8 (C1), 113.3 (C5), 56.1 (C8).

As previously reported, ${ }^{\mathrm{S} 6}$ HL5 was obtained in $37 \%$ yield (mp. $116-117{ }^{\circ} \mathrm{C}$ lit. 116.0-116.5 ${ }^{\circ} \mathrm{C}^{\mathrm{S7}}$ ). ${ }^{1} \mathrm{H}$ NMR: $\delta \mathrm{H}\left(400.13 \mathrm{MHz}, \mathrm{CDCl}_{3}, \mathrm{Me}_{4} \mathrm{Si}\right) 9.68(1 \mathrm{H}, \mathrm{s}, \mathrm{C}-\mathrm{OH}), 8.24(1 \mathrm{H}, \mathrm{dd}, \mathrm{J}=0.5,0.4$ Hz, H7), 7.40 (1H, s, N-OH), $7.33(1 \mathrm{H}, \mathrm{dd}, \mathrm{J}=8.6,2.5 \mathrm{~Hz}, \mathrm{H} 4), 7.15$ (1H, ddd, J= 2.5, 0.4, 0.4 $\mathrm{Hz} \mathrm{H6}), 6.93(1 \mathrm{H}, \mathrm{ddd}, \mathrm{J}=8.6,0.5,0.4 \mathrm{~Hz} \mathrm{H} 3), 1.30(9 \mathrm{H}, \mathrm{s}, \mathrm{H} 9) .{ }^{13} \mathrm{C}\left\{{ }^{1} \mathrm{H}\right\} \mathrm{NMR}: \delta \mathrm{C}(75.5 \mathrm{MHz}$, $\left.\mathrm{CDCl}_{3}, \mathrm{Me}_{4} \mathrm{Si}\right) 155.1$ (C2), 153.7 (C7), 142.6 (C5), 128.8 (C4/6), 127.5 (C4/ 6), 116.4 (C3), 115.7 (C1), $34.1(\mathrm{C} 8), 31.5(\mathrm{C} 9)$.

HL6 was obtained in $77 \%$ yield (mp. $117.8-119.6{ }^{\circ} \mathrm{C}$ lit. $\left.122{ }^{\circ} \mathrm{C}^{\mathrm{s} 8}\right) .{ }^{1} \mathrm{H}$ NMR: $\delta \mathrm{H}(400.13$ $\left.\mathrm{MHz}, \mathrm{CDCl}_{3}, \mathrm{Me}_{4} \mathrm{Si}\right) 9.41(1 \mathrm{H}, \mathrm{s}, \mathrm{C}-\mathrm{OH}), 8.18(1 \mathrm{H}, \mathrm{dd}, \mathrm{J}=0.4,0.4 \mathrm{~Hz}, \mathrm{H} 7), 7.43(1 \mathrm{H}, \mathrm{s}$, $\mathrm{NOH}), 6.92(1 \mathrm{H}, \mathrm{m}, \mathrm{H} 3 / 4), 6.88(1 \mathrm{H}, \mathrm{m}, \mathrm{H3} / 4), 6.69(1 \mathrm{H}, \mathrm{dt}, \mathrm{J}=2.8,0.4 \mathrm{~Hz}, \mathrm{H} 6), 3.78(3 \mathrm{H}, \mathrm{s}$, H8).

HL7 was obtained in $83 \%$ yield (mp. $138.0-139.6{ }^{\circ} \mathrm{C}$ lit. $\left.136{ }^{\circ} \mathrm{C}^{\mathrm{s} 9}\right) .{ }^{1} \mathrm{H}$ NMR: $\delta \mathrm{H}(400.13$ $\left.\mathrm{MHz}_{\mathrm{CDCl}}, \mathrm{Me}_{4} \mathrm{Si}\right) 10.0(1 \mathrm{H}, \mathrm{s}, \mathrm{C}-\mathrm{OH}), 8.19(1 \mathrm{H}, \mathrm{dd}, \mathrm{J}=0.4,0.4 \mathrm{~Hz}, \mathrm{H} 7), 7.22$ (1H, s, br, $\mathrm{NOH}), 7.10(1 \mathrm{H}, \mathrm{m}, \mathrm{H} 6), 6.54(1 \mathrm{H}, \mathrm{m}, \mathrm{H} 3), 6.51(1 \mathrm{H}, \mathrm{m}, \mathrm{H} 5), 3.83\left(3 \mathrm{H}, \mathrm{s}, \mathrm{OCH}_{3}\right)$.

HL8 was obtained in $43 \%$ yield (mp. $127.0-130.0{ }^{\circ} \mathrm{C}$ lit. $133-134.5^{\circ} \mathrm{C}^{\mathrm{S} 10}$ ). ${ }^{1} \mathrm{H}$ NMR: $\delta \mathrm{H}$ (400.13 MHz, CDCl, $\left.\mathrm{Me}_{4} \mathrm{Si}\right) 9.79$ (1H, s, C-OH), 8.15 (1H, dd, J = 0.4, 0.4 Hz, H7), 7.37 (1H, s, br, N-OH), 7.37 (1H, dd, J = 8.8, 2.5 Hz, H4), 7.30 (1H, ddd, J = 2.4, 0.4, 0.4 Hz, H6), 6.88 
$(1 \mathrm{H}, \mathrm{ddd}, \mathrm{J}=8.8,0.4,0.4 \mathrm{~Hz}, \mathrm{H} 3) .{ }^{13} \mathrm{C}\left\{{ }^{1} \mathrm{H}\right\} \mathrm{NMR}: \delta \mathrm{C}\left(125.8 \mathrm{MHz}, \mathrm{CDCl}_{3}, \mathrm{Me}_{4} \mathrm{Si}\right) 156.5(\mathrm{C} 2)$, 152.0 (C7), 134.1 (C4), 133.0 (C6), 118.8 (C3), 118.1 (C1), 111.4 (C5).

HL9 was obtained in $85 \%$ yield (mp. $115.0-116.2{ }^{\circ} \mathrm{C}$ lit. $\left.100{ }^{\circ} \mathrm{C}^{\mathrm{S}}\right) .{ }^{1} \mathrm{H}$ NMR: $\delta \mathrm{H}(400.13$ $\left.\mathrm{MHz}_{\mathrm{CDCl}}, \mathrm{Me}_{4} \mathrm{Si}\right) 9.86$ (1H, s, C-OH), 8.24 (1H, s, H7), 7.86 (1H, s, br, NOH), 6.93-6.92 $(3 \mathrm{H}, \mathrm{m}, \mathrm{H} 4+5+6), 4.13(2 \mathrm{H}, \mathrm{q}, \mathrm{J}=7.0 \mathrm{~Hz}, \mathrm{H} 8), 1.48(3 \mathrm{H}, \mathrm{t}, \mathrm{J}=7 \mathrm{~Hz}, \mathrm{H} 9)$.

\section{Synthesis of the bis(oximato)copper(II) complexes}

Bis(oximato)copper(II) complexes (with formula $\mathrm{Cu}(\mathbf{L N})_{2}$, denoted $\mathbf{N}$, using the numbering scheme of the main text) were prepared using the following general protocol. The prepared ligand $(1 \mathrm{mmol})$ in ethanol $\left(12 \mathrm{~cm}^{3}\right)$ was added to a hot solution of $0.02 \mathrm{M}$ aqueous copper sulfate $\left(25 \mathrm{~cm}^{3}, 0.5 \mathrm{mmol}\right)$. The mixture was stirred for 15 minutes to afford a pale green-brown precipitate, which was washed with water and dried in air. Powder X-ray diffraction data were collected on a STOE STADIP instrument operated in capillary Debye-Scherrer mode equipped with a $\mathrm{Cu}$ X-ray tube, a primary beam monochromator $\left(\mathrm{CuK}_{\alpha 1}\right)$ and a scintillation position-sensitive linear detector. $2 \theta$ ranges of $3-70^{\circ}$ were investigated over $16 \mathrm{~h}$ of acquisition time and samples were packed in $0.7 \mathrm{~mm}$ glass capillaries.

$\mathbf{1}$ was obtained in $47 \%$ yield. Fig. S1.1 shows the pXRD pattern of $\mathbf{1}$ and the simulated pXRD patterns for the two known polymorphs, ${ }^{\text {S11 }}$ with CSD entry codes SALCOP03 (polymeric $\left[\mathrm{Cu}(\mathbf{L 1})_{2}\right]_{\mathrm{n}}$ ) and SALCOP04 (monomeric $\left.\mathrm{Cu}(\mathbf{L 1})_{2}\right)$, confirming the monomeric nature of this sample. 


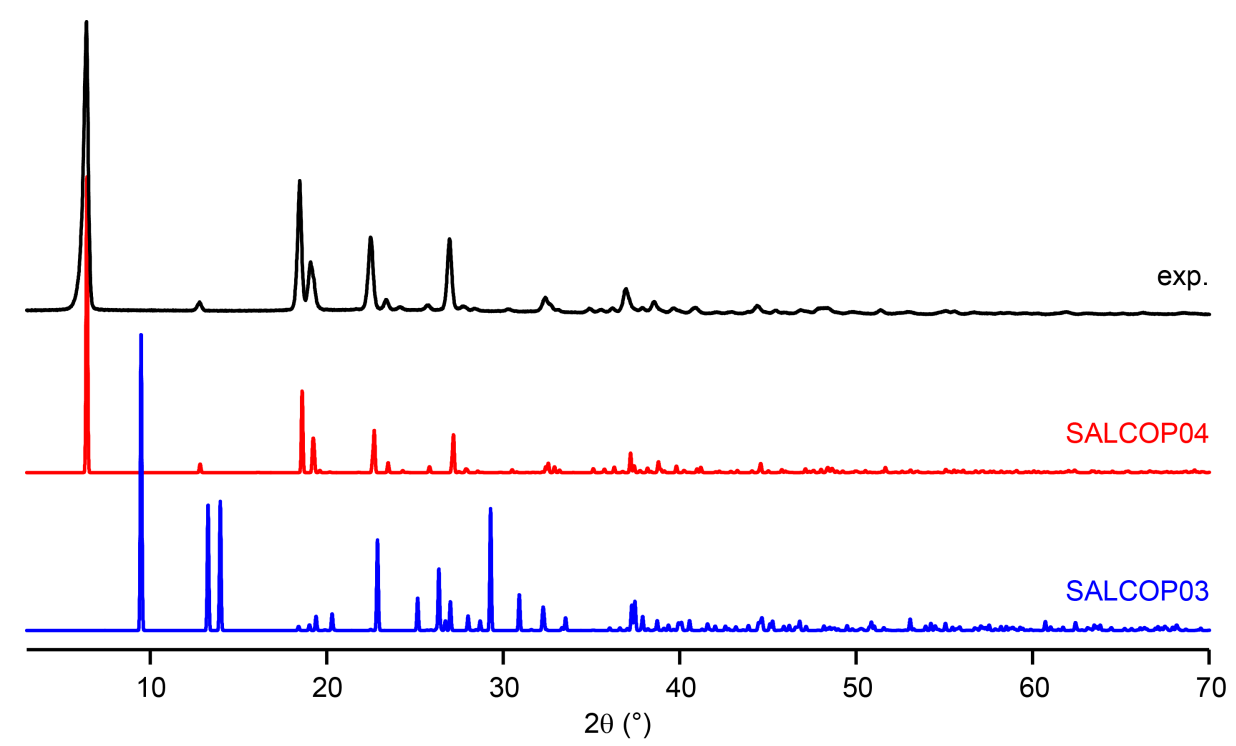

Fig. S1.1. Experimental pXRD pattern of $\mathbf{1}$ and patterns simulated for CSD entries SALCOP03 and SALCOP04 ${ }^{\mathrm{S11}}$.

2 was obtained in $49 \%$ yield. Fig. S1.2 shows the pXRD pattern of 2.

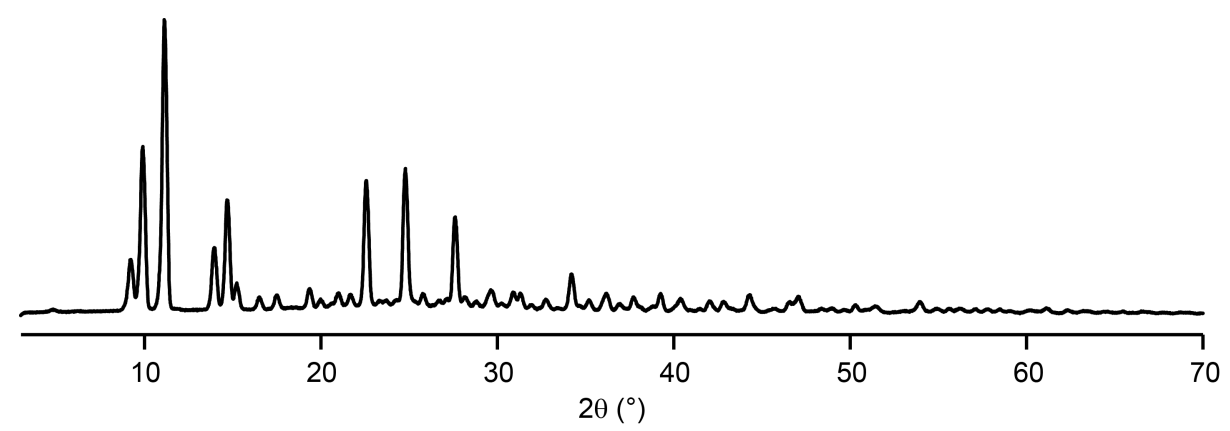

Fig. S1.2. Experimental pXRD pattern of 2.

3 was obtained in 91\% yield. Fig. S1.3 shows the pXRD pattern of 3.

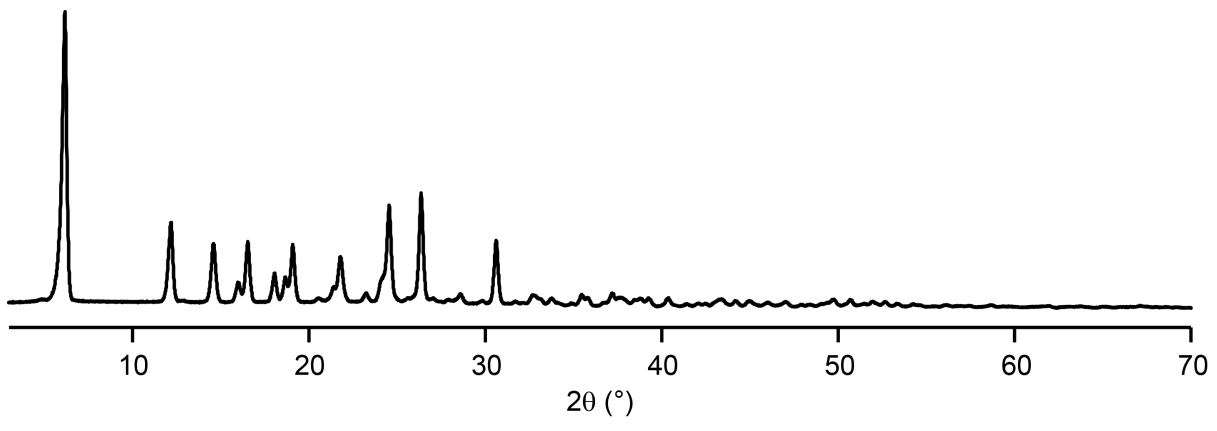

Fig. S1.3. Experimental pXRD pattern of 3. 
4 was obtained in $86 \%$ yield. Fig. S1.4 shows the pXRD pattern of 4 .

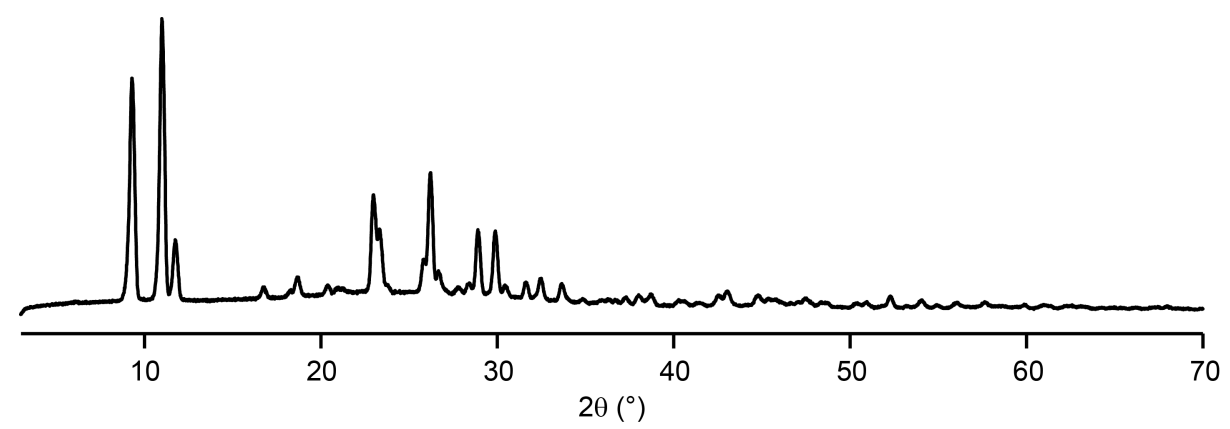

Fig. S1.4. Experimental pXRD pattern of 4 .

5 was obtained in $27 \%$ yield. Fig. S1.5 shows the pXRD pattern of 5 .

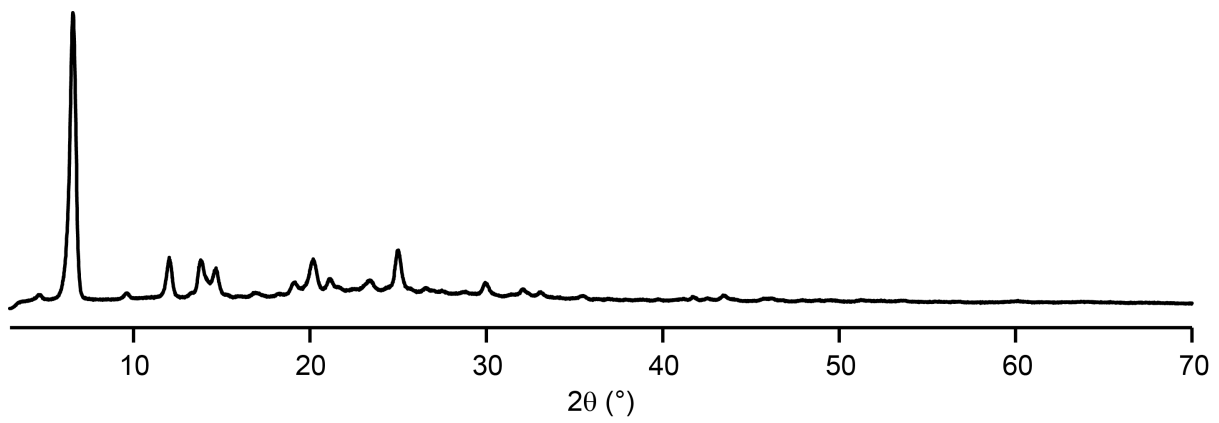

Fig. S1.5. Experimental pXRD pattern of $\mathbf{5}$.

6 was obtained in $68 \%$ yield. Fig. S1.6 shows the pXRD pattern of 6 .

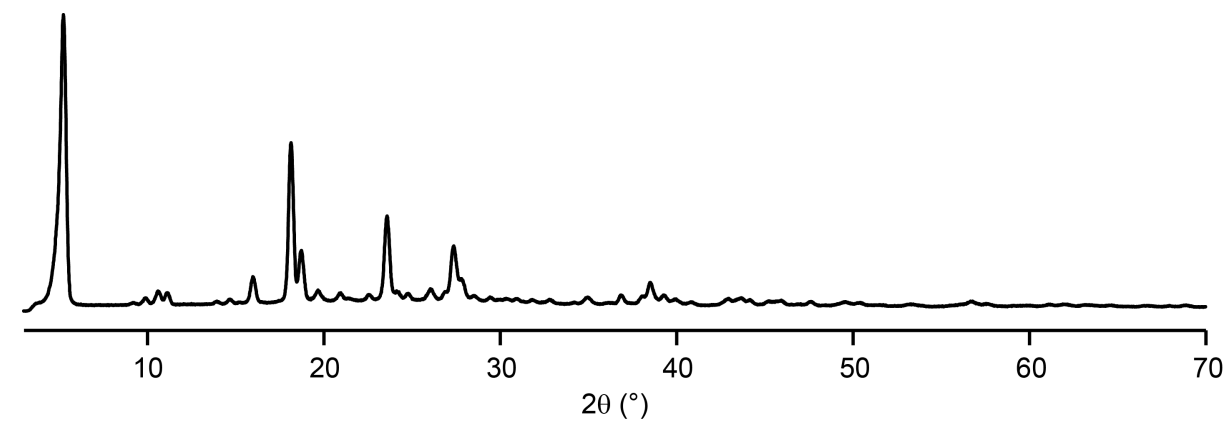

Fig. S1.6. Experimental pXRD pattern of 6 .

7 was obtained in $76 \%$ yield. To obtain the polymorph of 7 discussed in the text, the sample was heated at $110{ }^{\circ} \mathrm{C}$ overnight. ${ }^{S 12}$ Fig. S1.7 shows the pXRD patterns of 7 before and after heating. 


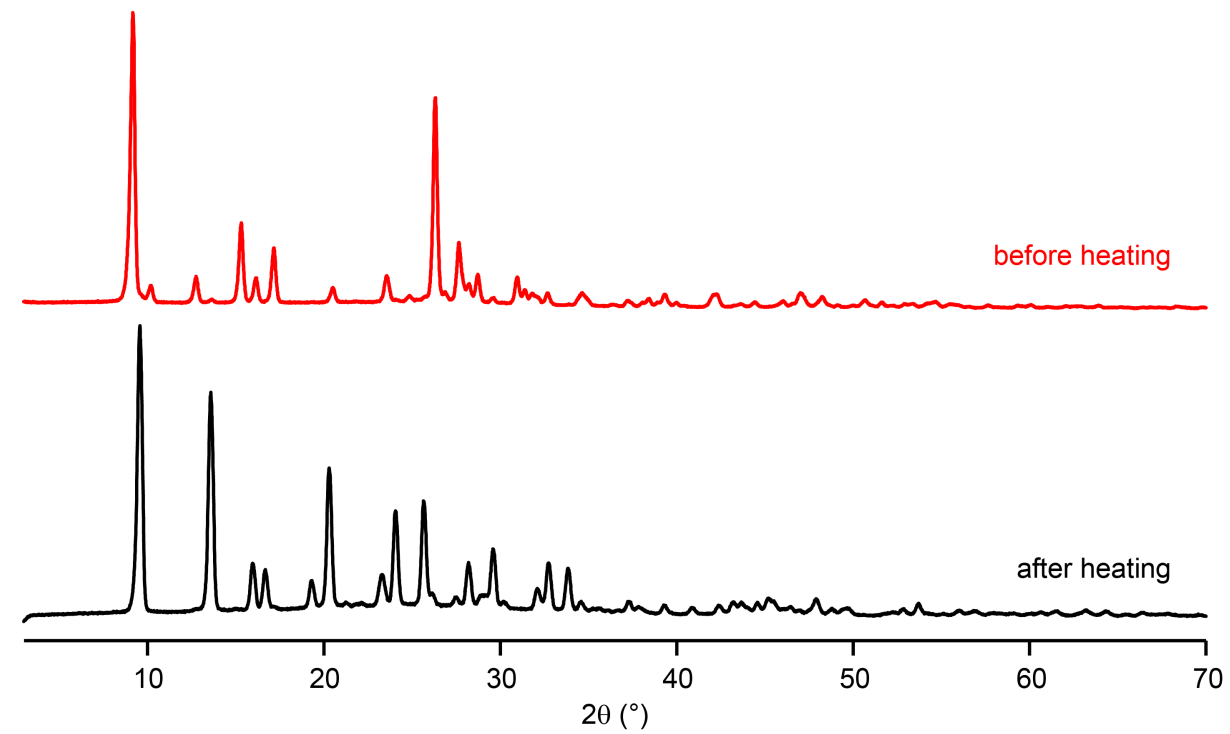

Fig. S1.7. Experimental pXRD patterns of 7 before (red) and after (black) heating at $110^{\circ} \mathrm{C}$ overnight.

8 was obtained in $75 \%$ yield. Fig. S1.8 shows the pXRD pattern of 8.

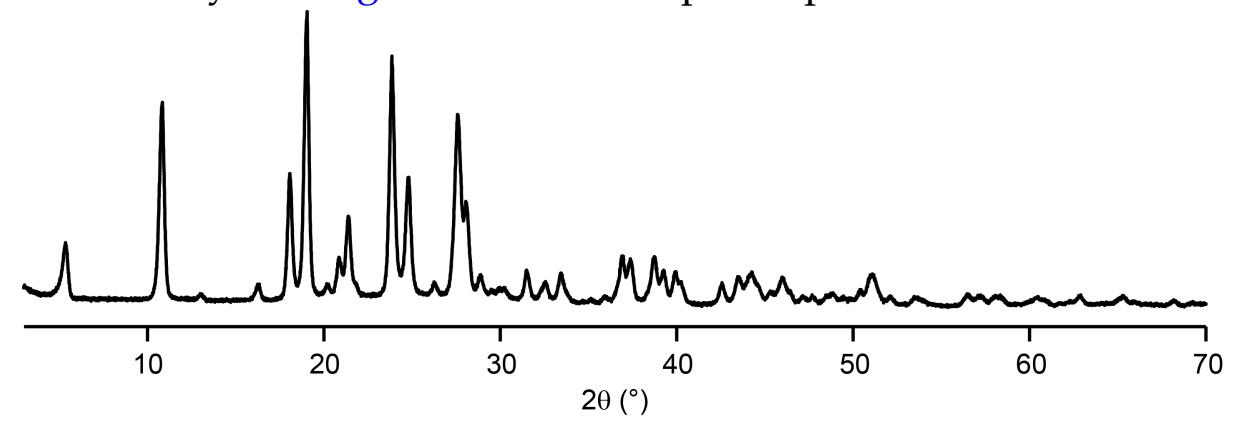

Fig. S1.8. Experimental pXRD pattern of 8.

9 was obtained in 70\% yield. Fig. S1.9 shows the pXRD pattern of 9.

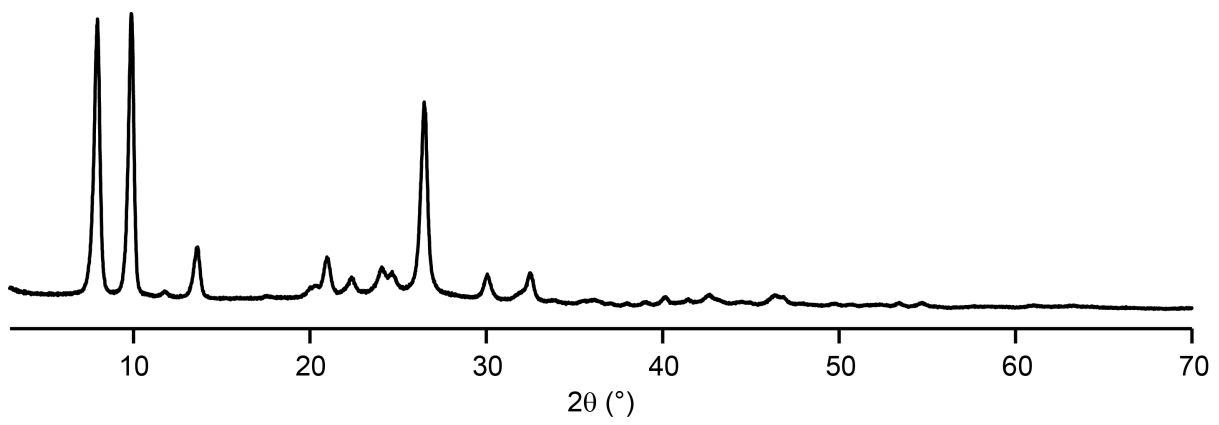

Fig. S1.9. Experimental pXRD pattern of 9. 


\section{S2. Computational Details}

The calculation of pNMR parameters employed the methodology introduced in Ref. S1; i.e., structures were optimised with the Gaussian $09^{\mathrm{S13}}$ at the PBE0-D3 ${ }^{\mathrm{S14}-\mathrm{S} 20}$ level of density functional theory, employing a Wachters basis ${ }^{521,522}$ augmented with two diffuse $p$ and one diffuse $d$ sets for $\mathrm{Cu}(8 \mathrm{~s} 7 \mathrm{p} 4 \mathrm{~d}), 6-31 \mathrm{G}^{* *}$ for the $\mathrm{H}(\mathrm{br})$ atoms and $6-31 \mathrm{G}^{*}$ for all other atoms. The $\sigma_{\text {orb }}, g$ and A tensors were computed at the PBE0-1/3 $3^{\text {s23 }}$ level using a 9s7p4d basis set on $\mathrm{Cu}$ that was constructed specifically for hyperfine coupling constant calculations, $^{\mathrm{S} 24}$ and the IGLO-II basis ${ }^{\mathrm{S} 25}$ on the ligands. The $\sigma_{\mathrm{orb}}$ calculations employed gauge-including atomic orbitals and fine integration grids as implemented in Gaussian 09. The $\mathrm{g}$ and A tensors were computed with $\mathrm{ORCA}^{\mathrm{S} 26}$ (tight SCF convergence and fine integration grid, Grid5 option). Isotropic magnetic shielding constants $\sigma_{\text {iso }}$ were computed using the formalism given in Ref. S27, where the effective spin (1/2 in our case), the temperature (set to $298.15 \mathrm{~K}$ ), and the isotropic and anisotropic parts of the A and $\mathrm{g}$ tensors enter explicitly. Chemical shifts $\delta_{\text {iso }}$ are reported relative to TMS according to $\delta_{\text {iso }}=$ $\sigma_{\text {orb }}($ TMS $)-\sigma_{\text {iso }}$ where the isotropic orbital shieldings of TMS have been computed at the same level.

As described in the main text, the partial s character of the HOMO on atoms close to the $\mathrm{Cu}$ leads to large computed hyperfine couplings for these nuclei. As an example, Table S2.1 gives the contributions from $\mathrm{C}$ and $\mathrm{H}$ to the $\alpha-\mathrm{HOMO}$ for 6 . 
Table S2.1. Orbital coefficients for C and H (PBE0-1/3 / IGLO-II) for the $\alpha-H O M O$ of $6 .{ }^{a}$

\begin{tabular}{|c|c|c|c|c|c|c|c|c|}
\hline Atom & Orbital & Occupancy & Atom & Orbital & Occupancy & Atom & Orbital & Occupancy \\
\hline \multirow[t]{6}{*}{$\mathrm{H} 3$} & $1 S$ & 0.00417 & $\mathrm{C} 2$ & $1 S$ & -0.00232 & C6 & $1 S$ & 0.00338 \\
\hline & $2 S$ & 0.00712 & & $2 S$ & -0.00353 & & $2 S$ & 0.00495 \\
\hline & $3 S$ & 0.00371 & & $3 S$ & -0.00040 & & $3 S$ & 0.00138 \\
\hline & $4 \mathrm{PX}$ & 0.00102 & & $4 S$ & 0.00812 & & $4 S$ & -0.01508 \\
\hline & $4 \mathrm{PY}$ & -0.00046 & & $5 S$ & 0.04326 & & $5 S$ & -0.03702 \\
\hline & $4 \mathrm{PZ}$ & 0.00000 & & $6 \mathrm{PX}$ & -0.01129 & & $6 \mathrm{PX}$ & -0.00175 \\
\hline \multirow[t]{6}{*}{$\mathrm{H} 4$} & $1 S$ & -0.01430 & & $6 P Y$ & -0.00481 & & $6 P Y$ & 0.00262 \\
\hline & $2 S$ & -0.02492 & & $6 \mathrm{PZ}$ & 0.00000 & & $6 \mathrm{PZ}$ & 0.00000 \\
\hline & $3 S$ & -0.01319 & & $7 P X$ & -0.03754 & & $7 P X$ & -0.00481 \\
\hline & $4 \mathrm{PX}$ & 0.00115 & & 7PY & -0.01358 & & 7PY & 0.00781 \\
\hline & 4PY & -0.00053 & & 7PZ & 0.00000 & & 7PZ & 0.00000 \\
\hline & $4 \mathrm{PZ}$ & 0.00000 & & $8 \mathrm{PX}$ & -0.03334 & & $8 \mathrm{PX}$ & -0.00901 \\
\hline \multirow[t]{6}{*}{ H6 } & $1 S$ & 0.00866 & & $8 \mathrm{PY}$ & -0.02481 & & $8 \mathrm{PY}$ & 0.00979 \\
\hline & $2 S$ & 0.01770 & & $8 \mathrm{PZ}$ & 0.00000 & & $8 \mathrm{PZ}$ & 0.00000 \\
\hline & $3 S$ & 0.01633 & & 9PX & -0.05697 & & 9PX & 0.01088 \\
\hline & $4 \mathrm{PX}$ & -0.00007 & & 9PY & 0.03514 & & 9PY & 0.03933 \\
\hline & $4 \mathrm{PY}$ & -0.00037 & & 9PZ & 0.00000 & & 9PZ & 0.00000 \\
\hline & $4 \mathrm{PZ}$ & 0.00000 & $\mathrm{C} 3$ & $1 S$ & 0.01001 & $\mathrm{C} 7$ & $1 S$ & 0.01020 \\
\hline \multirow[t]{6}{*}{ H7 } & $1 S$ & 0.03191 & & $2 S$ & 0.01415 & & $2 S$ & 0.01480 \\
\hline & $2 S$ & 0.06192 & & $3 S$ & 0.00550 & & $3 S$ & 0.00470 \\
\hline & $3 S$ & 0.05814 & & $4 S$ & -0.04972 & & $4 S$ & -0.05270 \\
\hline & $4 \mathrm{PX}$ & 0.00274 & & $5 S$ & -0.10215 & & $5 S$ & -0.06639 \\
\hline & $4 \mathrm{PY}$ & -0.00005 & & $6 \mathrm{PX}$ & 0.01120 & & $6 \mathrm{PX}$ & -0.00529 \\
\hline & $4 \mathrm{PZ}$ & 0.00000 & & $6 \mathrm{PY}$ & 0.01078 & & $6 \mathrm{PY}$ & 0.01038 \\
\hline \multirow[t]{6}{*}{ H8 } & $1 S$ & -0.00093 & & $6 \mathrm{PZ}$ & 0.00000 & & $6 \mathrm{PZ}$ & 0.00000 \\
\hline & $2 S$ & -0.00125 & & $7 P X$ & 0.03261 & & $7 \mathrm{PX}$ & -0.01636 \\
\hline & $3 S$ & -0.00166 & & 7PY & 0.03254 & & 7PY & 0.03041 \\
\hline & $4 \mathrm{PX}$ & 0.00012 & & 7PZ & 0.00000 & & 7PZ & 0.00000 \\
\hline & 4PY & 0.00009 & & $8 \mathrm{PX}$ & 0.05884 & & $8 \mathrm{PX}$ & -0.01787 \\
\hline & $4 \mathrm{PZ}$ & 0.00021 & & $8 \mathrm{PY}$ & 0.04965 & & $8 \mathrm{PY}$ & 0.04870 \\
\hline \multirow[t]{5}{*}{$\mathrm{H} 8^{\prime}$} & $1 S$ & 0.00147 & & $8 \mathrm{PZ}$ & 0.00000 & & $8 \mathrm{PZ}$ & 0.00000 \\
\hline & $2 S$ & 0.00313 & & 9PX & 0.02417 & & 9PX & -0.03701 \\
\hline & $3 S$ & 0.00053 & & 9PY & -0.04716 & & 9PY & -0.02737 \\
\hline & $4 \mathrm{PX}$ & 0.00002 & & 9PZ & 0.00000 & & 9PZ & 0.00000 \\
\hline & 4PY & 0.00031 & $\mathrm{C} 4$ & $1 S$ & -0.00373 & $\mathrm{C} 8$ & $1 S$ & 0.00038 \\
\hline
\end{tabular}




\begin{tabular}{|c|c|c|c|c|c|c|c|}
\hline & $4 \mathrm{PZ}$ & 0.00000 & & $2 S$ & -0.00554 & $2 S$ & 0.00053 \\
\hline \multirow[t]{6}{*}{$\mathrm{H} 8^{\prime \prime}$} & $1 S$ & -0.00093 & & $3 S$ & -0.00138 & $3 S$ & 0.00021 \\
\hline & $2 S$ & -0.00125 & & $4 S$ & 0.01540 & $4 S$ & -0.00207 \\
\hline & $3 S$ & -0.00166 & & $5 S$ & 0.05598 & $5 S$ & -0.00251 \\
\hline & $4 \mathrm{PX}$ & 0.00012 & & $6 P X$ & -0.00258 & $6 \mathrm{PX}$ & -0.00032 \\
\hline & $4 P Y$ & 0.00009 & & $6 P Y$ & -0.00637 & $6 \mathrm{PY}$ & -0.00050 \\
\hline & $4 \mathrm{PZ}$ & -0.00021 & & $6 \mathrm{PZ}$ & 0.00000 & $6 \mathrm{PZ}$ & 0.00000 \\
\hline \multirow[t]{6}{*}{$\mathrm{Hbr}$} & $1 S$ & -0.01873 & & $7 \mathrm{PX}$ & -0.0075 & $7 \mathrm{PX}$ & -0.00099 \\
\hline & $2 S$ & -0.03642 & & 7PY & -0.01792 & $7 P Y$ & -0.00167 \\
\hline & $3 S$ & 0.03106 & & $7 \mathrm{PZ}$ & 0.00000 & $7 \mathrm{PZ}$ & 0.00000 \\
\hline & $4 \mathrm{PX}$ & -0.00065 & & $8 \mathrm{PX}$ & -0.01200 & $8 \mathrm{PX}$ & -0.00082 \\
\hline & $4 P Y$ & -0.01156 & & $8 P Y$ & -0.03076 & $8 \mathrm{PY}$ & -0.00165 \\
\hline & $4 \mathrm{PZ}$ & 0.00000 & & $8 \mathrm{PZ}$ & 0.00000 & $8 \mathrm{PZ}$ & 0.00000 \\
\hline \multirow[t]{20}{*}{$\mathrm{C} 1$} & $1 S$ & -0.00508 & & 9PX & 0.00708 & $9 P X$ & -0.00019 \\
\hline & $2 S$ & -0.00724 & & 9PY & -0.05525 & 9PY & -0.00258 \\
\hline & $3 S$ & -0.00266 & & 9PZ & 0.00000 & $9 \mathrm{PZ}$ & 0.00000 \\
\hline & $4 S$ & 0.02421 & C5 & $1 S$ & -0.00027 & & \\
\hline & $5 S$ & 0.05209 & & $2 S$ & -0.00036 & & \\
\hline & $6 \mathrm{PX}$ & 0.01351 & & $3 S$ & -0.00021 & & \\
\hline & $6 \mathrm{PY}$ & -0.00537 & & $4 S$ & 0.00155 & & \\
\hline & $6 \mathrm{PZ}$ & 0.00000 & & $5 S$ & 0.00477 & & \\
\hline & $7 \mathrm{PX}$ & 0.03895 & & $6 \mathrm{PX}$ & 0.00214 & & \\
\hline & $7 P Y$ & -0.01551 & & $6 \mathrm{PY}$ & -0.00001 & & \\
\hline & $7 \mathrm{PZ}$ & 0.00000 & & $6 \mathrm{PZ}$ & 0.00000 & & \\
\hline & $8 \mathrm{PX}$ & 0.07366 & & $7 P X$ & 0.00722 & & \\
\hline & $8 P Y$ & -0.02837 & & 7PY & 0.00039 & & \\
\hline & $8 \mathrm{PZ}$ & 0.00000 & & $7 \mathrm{PZ}$ & 0.00000 & & \\
\hline & $9 P X$ & -0.03755 & & $8 \mathrm{PX}$ & 0.00701 & & \\
\hline & $9 P Y$ & 0.03159 & & 8PY & -0.00186 & & \\
\hline & $9 \mathrm{PZ}$ & 0.00000 & & $8 \mathrm{PZ}$ & 0.00000 & & \\
\hline & & & & 9PX & 0.03805 & & \\
\hline & & & & 9PY & 0.00210 & & \\
\hline & & & & 9PZ & 0.00000 & & \\
\hline
\end{tabular}

a. Only occupancies of $\mathrm{s}$ and $\mathrm{p}$ orbitals are given (enumerated consecutively in the contracted [3s1p] and [5s4p] parts of the $\mathrm{H}$ and $\mathrm{C}$ basis sets, respectively). Note that the two equivalent ligands have the same s-orbital coefficients, whereas the p orbitals are equal in magnitude but opposite in sign. 


\section{S3. Solid-State NMR Details}

Solid-state NMR spectra were recorded using a Bruker Avance III spectrometer, equipped with a $14.1 \mathrm{~T}$ wide-bore superconducting magnet (at ${ }^{1} \mathrm{H}$ and ${ }^{13} \mathrm{C}$ Larmor frequencies of 600.13 and $150.94 \mathrm{MHz}$, respectively). Experiments were carried out using a $1.9 \mathrm{~mm}$ MAS probe, with MAS rates between 37.5 and $40 \mathrm{kHz} .{ }^{1} \mathrm{H}$ and ${ }^{13} \mathrm{C}$ peak positions are quoted in ppm relative to $\left(\mathrm{CH}_{3}\right)_{4} \mathrm{Si}$, using the $\mathrm{NH}_{3}$ and $\mathrm{CH}_{3}$ resonances of L-alanine (8.5 and 20.5 ppm, respectively) as secondary references. MAS spectra were recorded using a rotor-synchronised spin-echo pulse sequence with an echo duration of one rotor period. Signal averaging was carried out for $128-1024\left({ }^{1} \mathrm{H}\right)$ or $16384-122880$ transients $\left({ }^{13} \mathrm{C}\right)$ with a recycle interval of $100 \mathrm{~ms}$ in all cases. Where required, frequency-stepped acquisition was carried out with the transmitter offset incremented by $\sim 100\left(v_{1} \approx 125 \mathrm{kHz}\right.$ for ${ }^{1} \mathrm{H}$ and $\left.{ }^{13} \mathrm{C}\right)$ for each sub-spectrum. Heteronuclear correlation spectra were recorded using cross polarisation $(\mathrm{CP})$ from ${ }^{1} \mathrm{H}$ with a contact pulse (ramped for ${ }^{1} \mathrm{H}$ ) of $100 \mu \mathrm{s}$, and are the result of averaging between 440 and 2048 transients for each of between 16 and $192 t_{1}$ increments of $26.67 \mu \mathrm{s}$, with a repeat interval of $100 \mathrm{~ms}$. Where required, sub spectra were recorded at transmitter offsets on resonance for $\mathrm{C} 3+\mathrm{C} 7 / \mathrm{H} 7$ in addition to sub spectra on resonance for all other species. For example, for the spectra in Fig. 4 of the main text transmitter offsets of $-9 \mathrm{kHz}$ and $148 \mathrm{kHz}\left({ }^{1} \mathrm{H}\right)$ and $20 \mathrm{kHz}$ and $115 \mathrm{kHz}\left({ }^{13} \mathrm{C}\right)$ were used. In all experiments, the sample temperature was controlled using a Bruker BCU-II chiller and Bruker BVT/BVTB-3000 temperature controller and heater booster. The sample temperature (including frictional heating effects arising from sample spinning) was calibrated using the isotropic ${ }^{87} \mathrm{Rb}$ shift of solid $\mathrm{RbCl} .^{\mathrm{S} 28}$ 


\section{S4. One- and Two-Dimensional Solid-State NMR Spectra of 2-5 and 7-9.}

Fig. S4.1 shows the ${ }^{1} \mathrm{H}$ and ${ }^{13} \mathrm{C}$ MAS NMR spectra of 2. The resonances for $\mathrm{C} 3$ and $\mathrm{C7}$ (predicted by the calculations to be at 1146 and 951.7 ppm, respectively) are not observed experimentally. Both ${ }^{1} \mathrm{H}$ and ${ }^{13} \mathrm{C} \mathrm{T}_{1}$ relaxation constants are much smaller for 2 (on the order of 0.5-2 ms for both nuclei, data not presented) than the other complexes, perhaps suggesting that these resonances cannot be observed owing to a loss of signal intensity during the spin echo. Fig. S4.2 shows the ${ }^{1} \mathrm{H}-{ }^{13} \mathrm{C}$ CP HETCOR spectrum of 2.
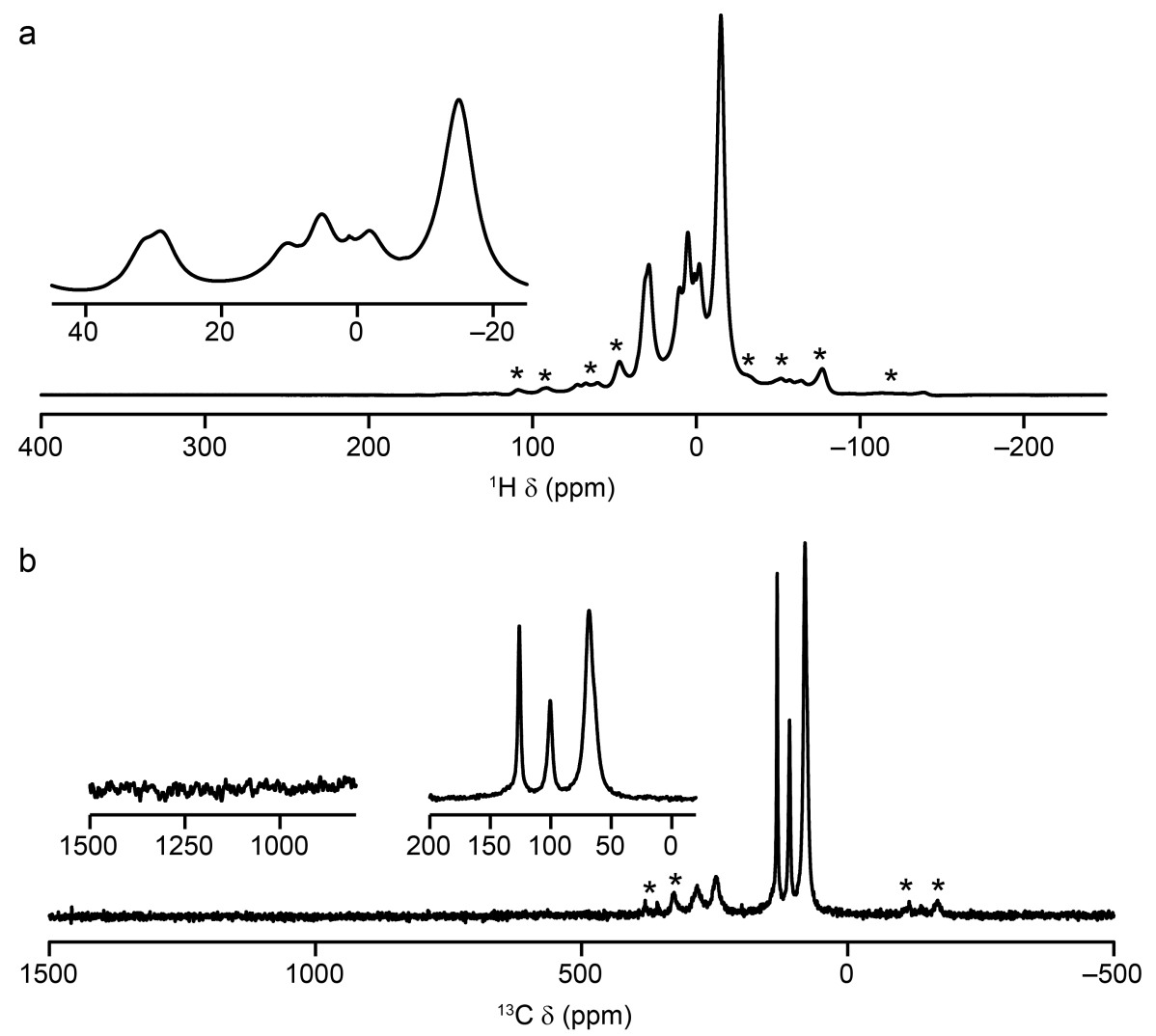

Fig. S4.1. (a) ${ }^{1} \mathrm{H}(14.1 \mathrm{~T}, 298 \mathrm{~K}, 37.5 \mathrm{kHz} \mathrm{MAS})$ and (b) ${ }^{13} \mathrm{C}(14.1 \mathrm{~T}, 298 \mathrm{~K}, 37.5 \mathrm{kHz} \mathrm{MAS})$ NMR spectra of 2 . Insets show expansions of closely-spaced resonances and (for $\left.{ }^{13} \mathrm{C}\right)$ the absence of the expected resonances at high shift. Spinning sidebands are marked by asterisks. 


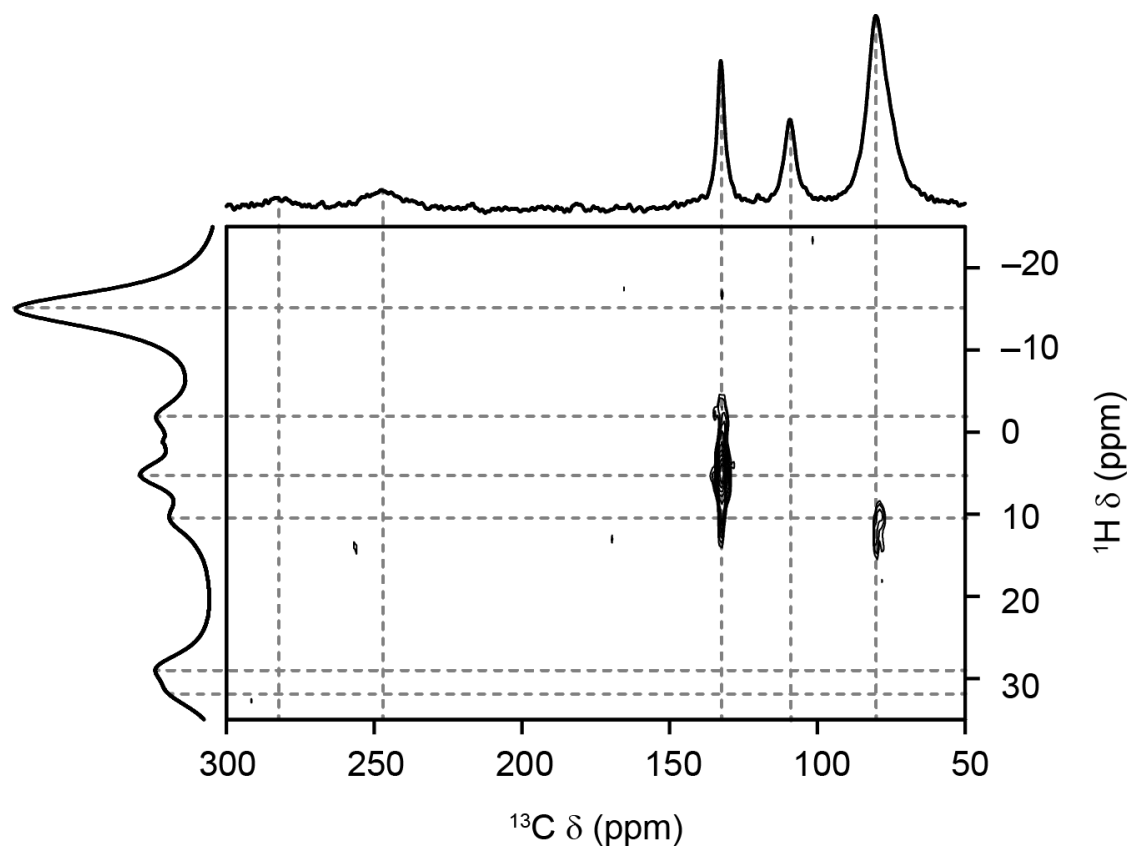

Fig. S4.2. ${ }^{1} \mathrm{H}-{ }^{13} \mathrm{C}(14.1 \mathrm{~T}, 298 \mathrm{~K}, 37.5 \mathrm{kHz}$ MAS) CP HETCOR spectrum of 2. Owing to the lack of high-frequency resonances in the MAS spectra, only one quadrant of the HETCOR was recorded.

Fig. S4.3 shows the ${ }^{1} \mathrm{H}$ and ${ }^{13} \mathrm{C}$ MAS NMR spectra of 3. Multiple resonances are observed for some chemically-equivalent sites (e.g., $\mathrm{H} 4$ at 35.9 and 33.6 ppm, see Fig. S4.3(a)), indicating crystallographic inequivalence - either the two ligands in the complex are inequivalent, or there are multiple crystallographically-distinct complexes within the unit cell. In the main text, average shifts and temperature dependence parameters were reported where multiple resonances were observed for a given chemical species. The individual shifts are reported in Section S5. Fig. S4.4 shows the ${ }^{1} \mathrm{H}-{ }^{13} \mathrm{C}$ CP HETCOR spectrum of 3 . 

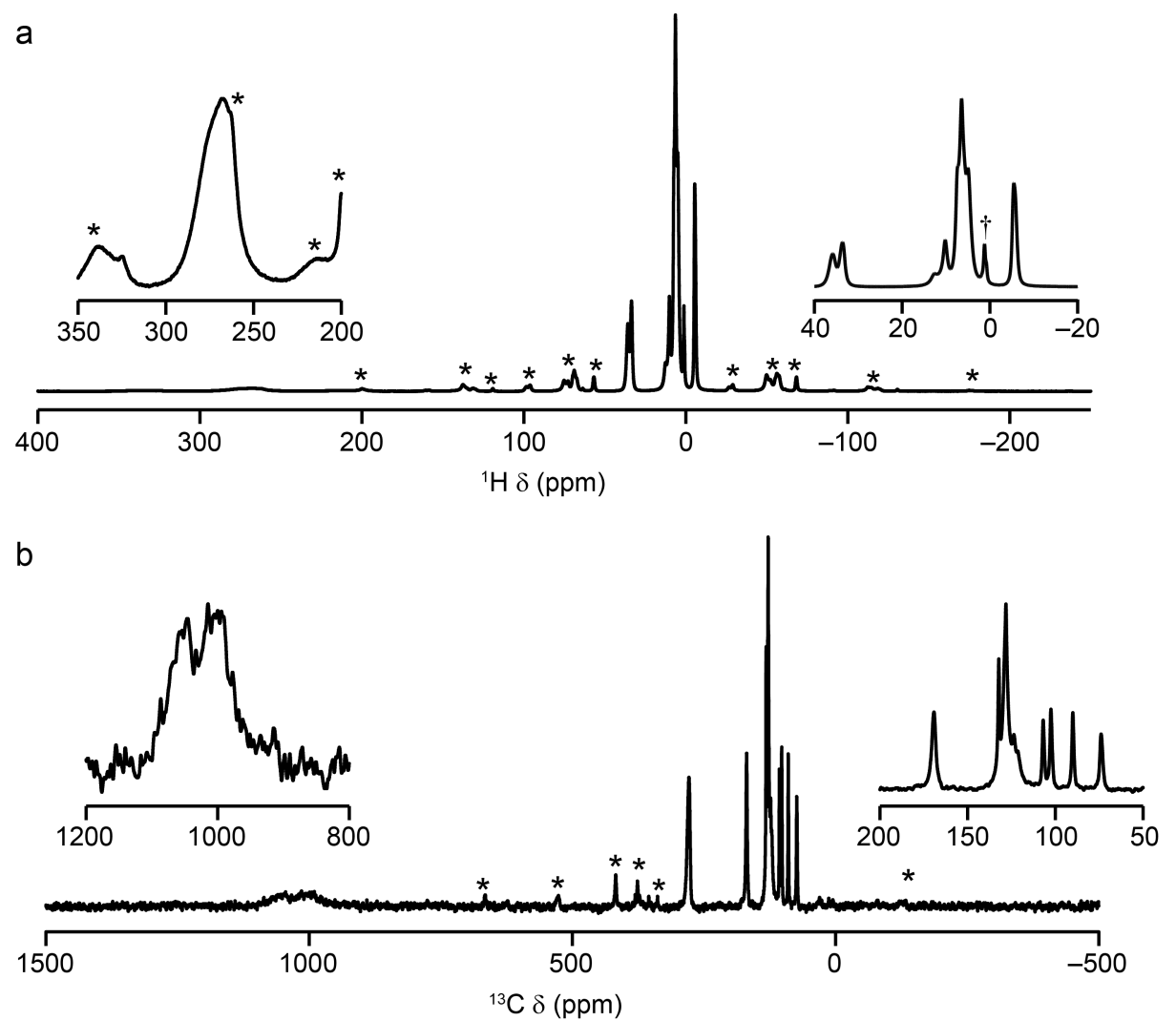

Fig. S4.3. (a) ${ }^{1} \mathrm{H}(14.1 \mathrm{~T}, 298 \mathrm{~K}, 37.5 \mathrm{kHz} \mathrm{MAS})$ and (b) ${ }^{13} \mathrm{C}(14.1 \mathrm{~T}, 298 \mathrm{~K}, 37.5 \mathrm{kHz} \mathrm{MAS})$ NMR spectra of 3. Insets show expansions of the most shifted and more closely-spaced resonances. Spinning sidebands are marked by asterisks and the dagger marks a ${ }^{1} \mathrm{H}$ resonance arising from a contaminant in the rotor cap.

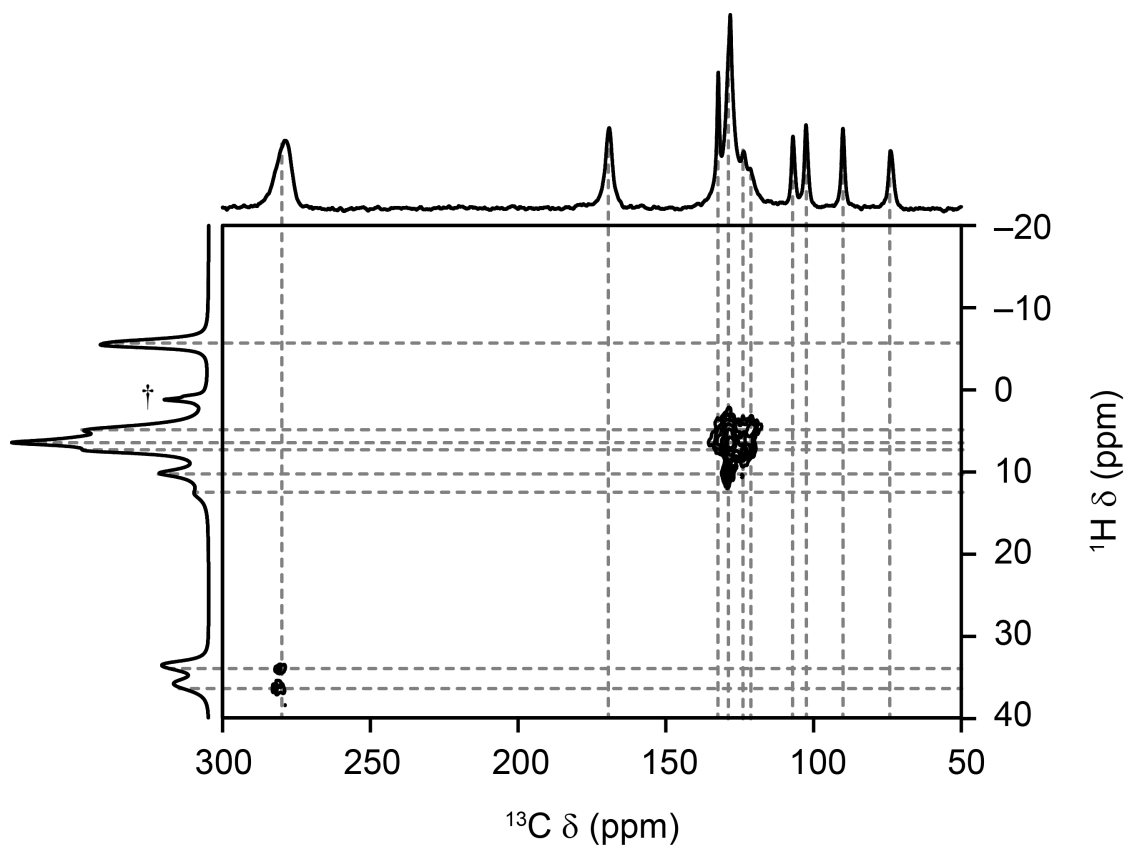

Fig. S4.4. ${ }^{1} \mathrm{H}-{ }^{13} \mathrm{C}(14.1 \mathrm{~T}, 298 \mathrm{~K}, 37.5 \mathrm{kHz}$ MAS) CP HETCOR spectrum of 3. The dagger marks a ${ }^{1} \mathrm{H}$ resonance arising from a contaminant in the rotor cap. 
Fig. S4.5 shows the ${ }^{1} \mathrm{H}$ and ${ }^{13} \mathrm{C}$ MAS NMR spectra of 4. Fig. S4.6 shows the ${ }^{1} \mathrm{H}-{ }^{13} \mathrm{C} C P$ HETCOR spectrum of 4 .

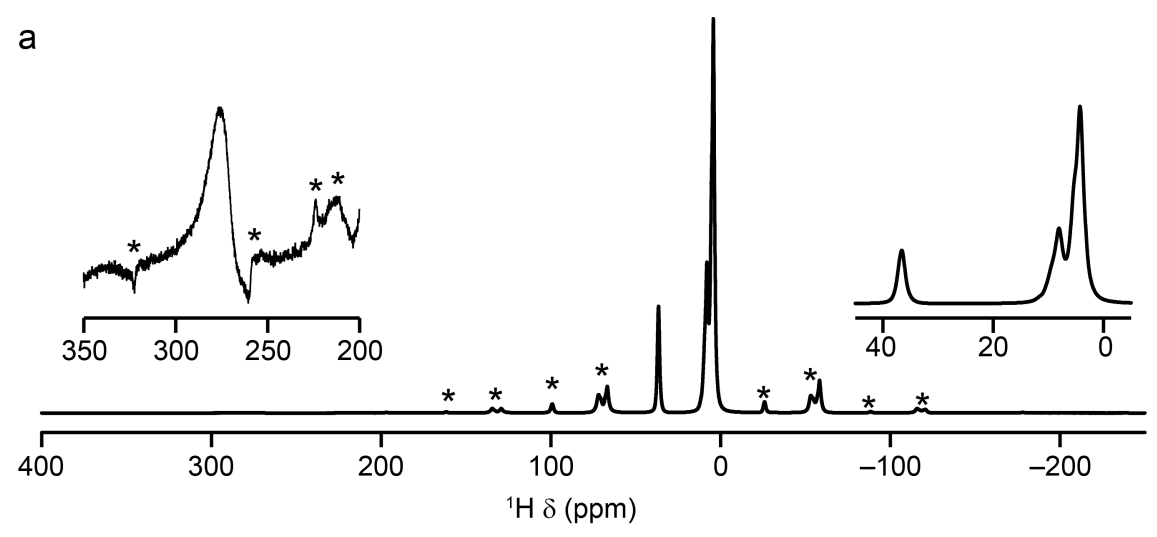

b

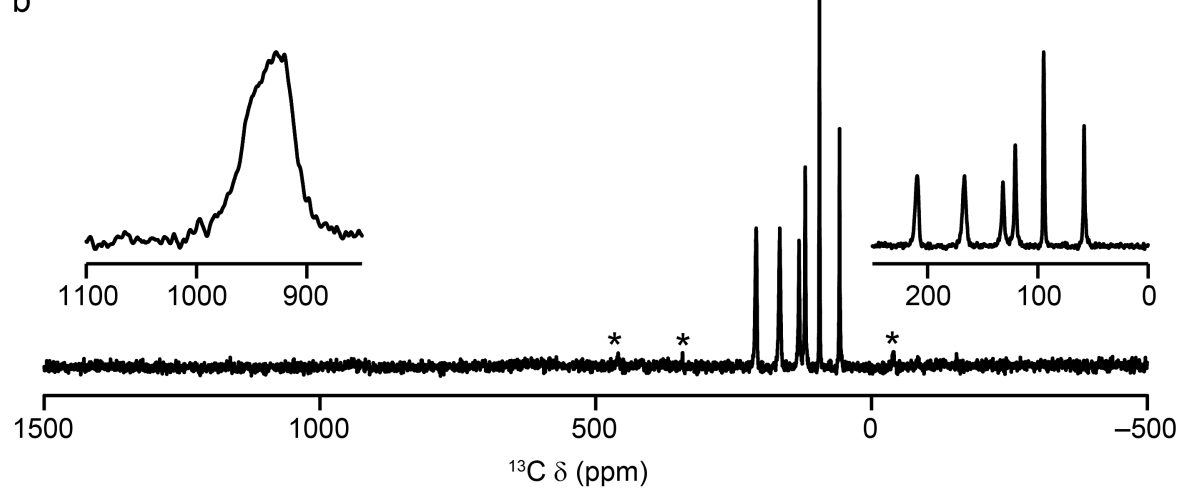

Fig. S4.5. (a) ${ }^{1} \mathrm{H}\left(14.1 \mathrm{~T}, 298 \mathrm{~K}, 37.5 \mathrm{kHz}\right.$ MAS) and (b) ${ }^{13} \mathrm{C}(14.1 \mathrm{~T}, 298 \mathrm{~K}, 37.5 \mathrm{kHz} \mathrm{MAS})$ NMR spectra of 4 . Insets show expansions of the most shifted and more closely-spaced resonances. Spinning sidebands are marked by asterisks.

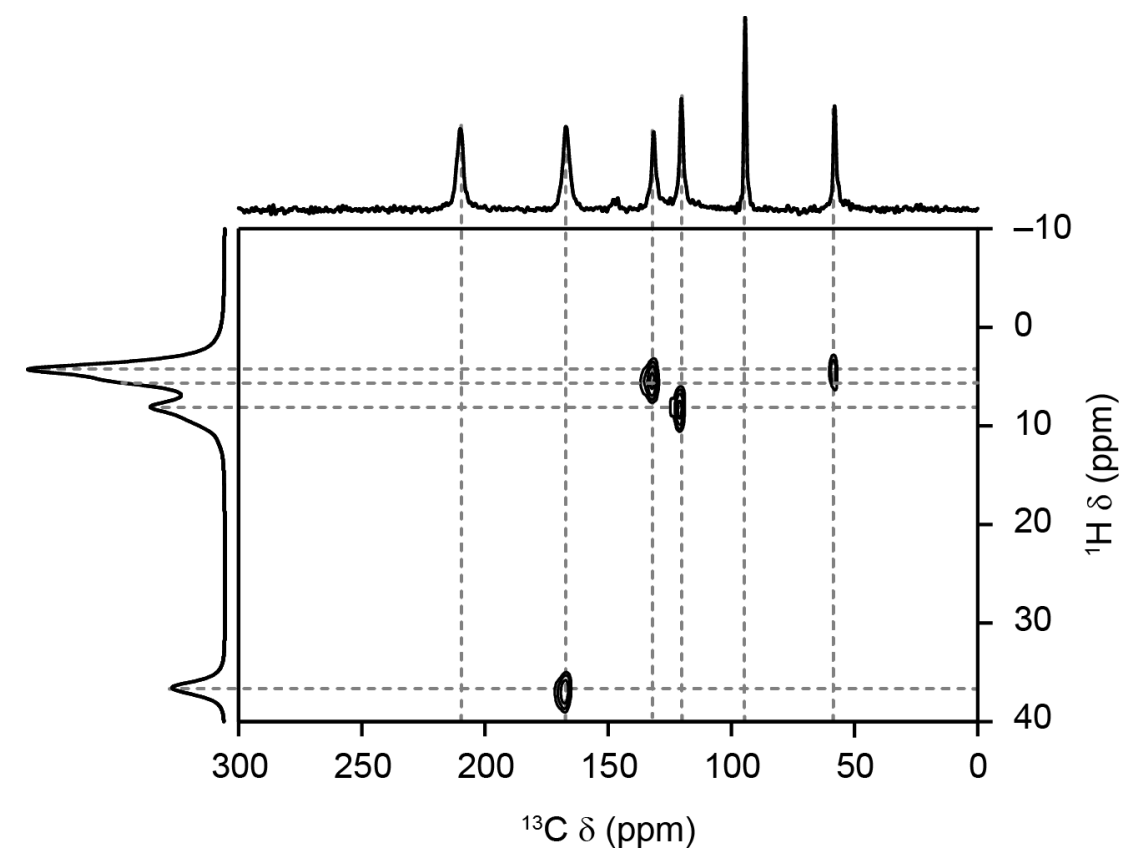

Fig. S4.6. ${ }^{1} \mathrm{H}^{13} \mathrm{C}(14.1 \mathrm{~T}, 298 \mathrm{~K}, 37.5 \mathrm{kHz}$ MAS) CP HETCOR spectrum of 4. 
Fig. S4.7 shows the ${ }^{1} \mathrm{H}$ and ${ }^{13} \mathrm{C}$ MAS NMR spectra of 5. The signal for C3 (see inset in Fig. S4.7(b)) is very broad and determining an accurate shift and temperature dependence is challenging. The large experimental errors (see Section S5) lead to the disagreement between experiment and computation in Fig. 5 of the main text. Fig. S4.8 shows the ${ }^{1} \mathrm{H}-{ }^{13} \mathrm{C}$ CP HETCOR spectrum of 5.
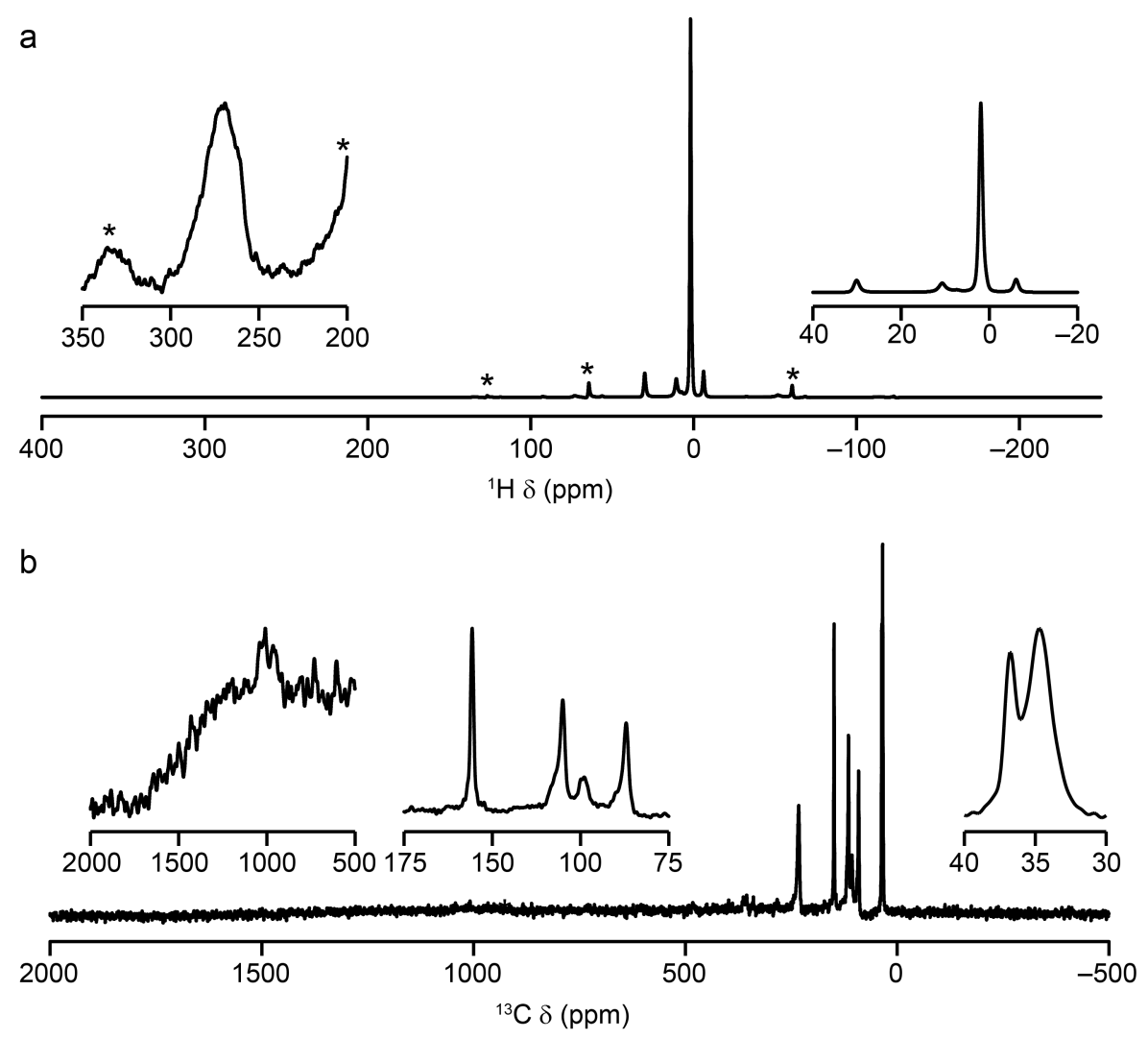

Fig. S4.7. (a) ${ }^{1} \mathrm{H}(14.1 \mathrm{~T}, 298 \mathrm{~K}, 37.5 \mathrm{kHz} \mathrm{MAS})$ and (b) ${ }^{13} \mathrm{C}(14.1 \mathrm{~T}, 298 \mathrm{~K}, 37.5 \mathrm{kHz} \mathrm{MAS})$ NMR spectra of 5. Insets show expansions of the most shifted and more closely-spaced resonances. Spinning sidebands are marked by asterisks. 


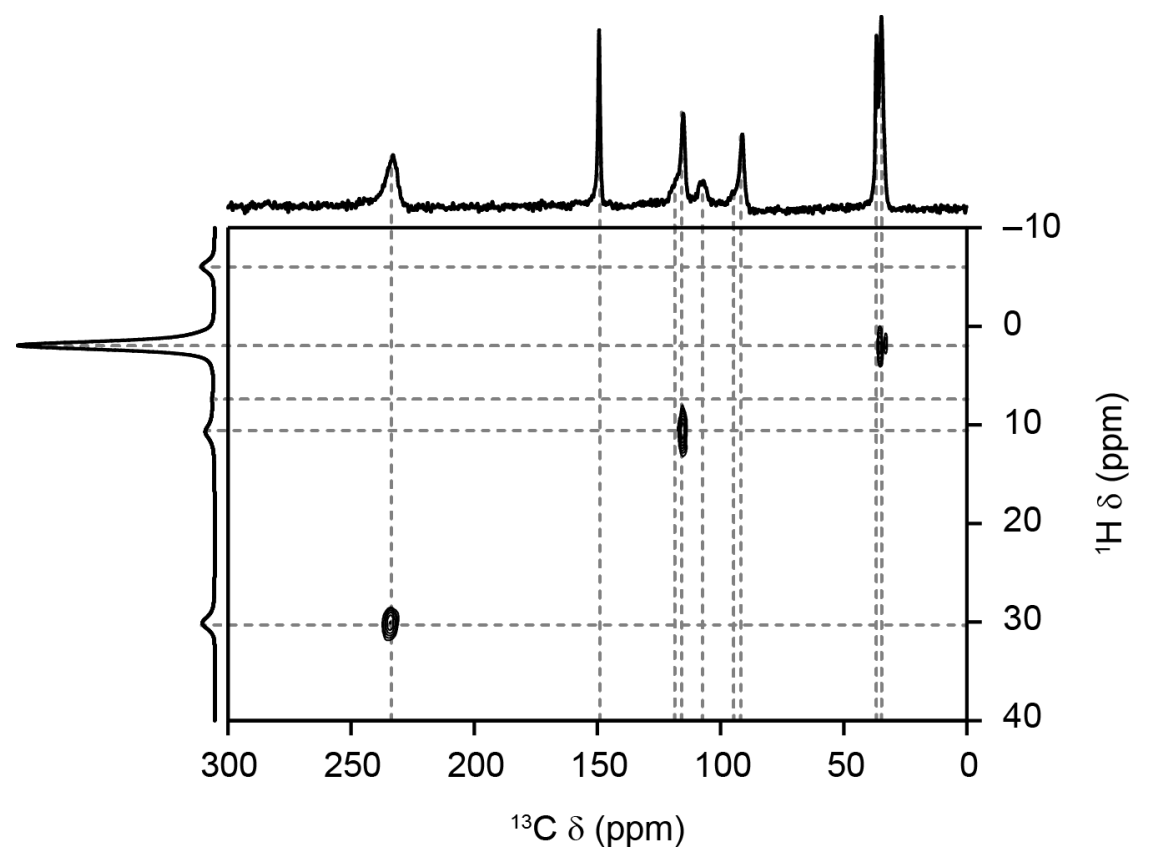

Fig. S4.8. ${ }^{1} \mathrm{H}-{ }^{13} \mathrm{C}(14.1 \mathrm{~T}, 298 \mathrm{~K}, 37.5 \mathrm{kHz}$ MAS) CP HETCOR spectrum of 5.

Fig. S4.9 shows the ${ }^{1} \mathrm{H}$ and ${ }^{13} \mathrm{C}$ MAS NMR spectra of 7 (after heating at $110{ }^{\circ} \mathrm{C}$ overnight). Fig. S4.10 shows the ${ }^{1} \mathrm{H}-{ }^{13} \mathrm{C} C P$ HETCOR spectrum of the same sample of 7 .
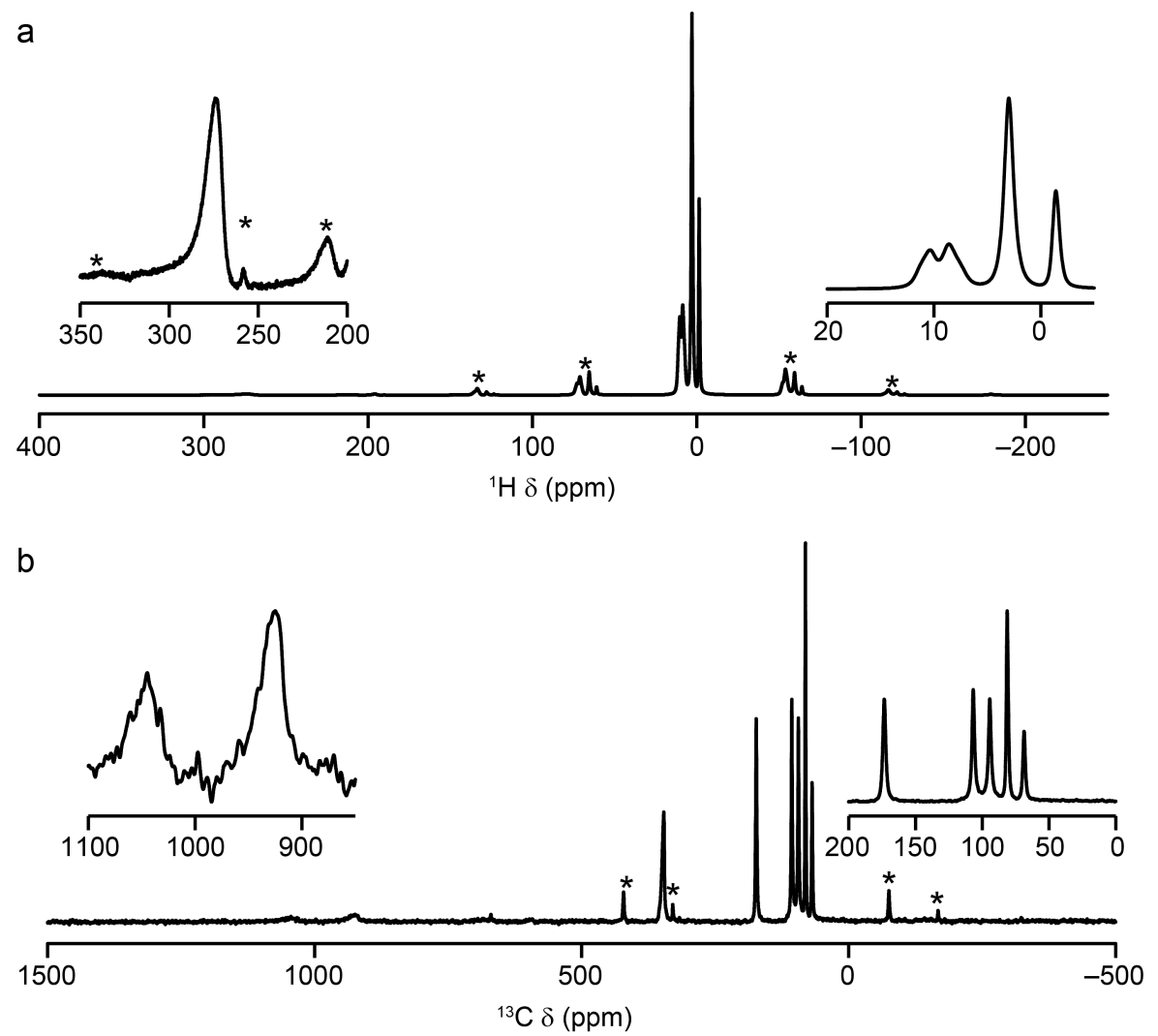

Fig. S4.9. (a) ${ }^{1} \mathrm{H}\left(14.1 \mathrm{~T}, 298 \mathrm{~K}, 37.5 \mathrm{kHz}\right.$ MAS) and (b) ${ }^{13} \mathrm{C}(14.1 \mathrm{~T}, 298 \mathrm{~K}, 37.5 \mathrm{kHz}$ MAS) NMR spectra of 7. Insets show expansions of the most shifted and more closely-spaced resonances. Spinning sidebands are marked by asterisks. 


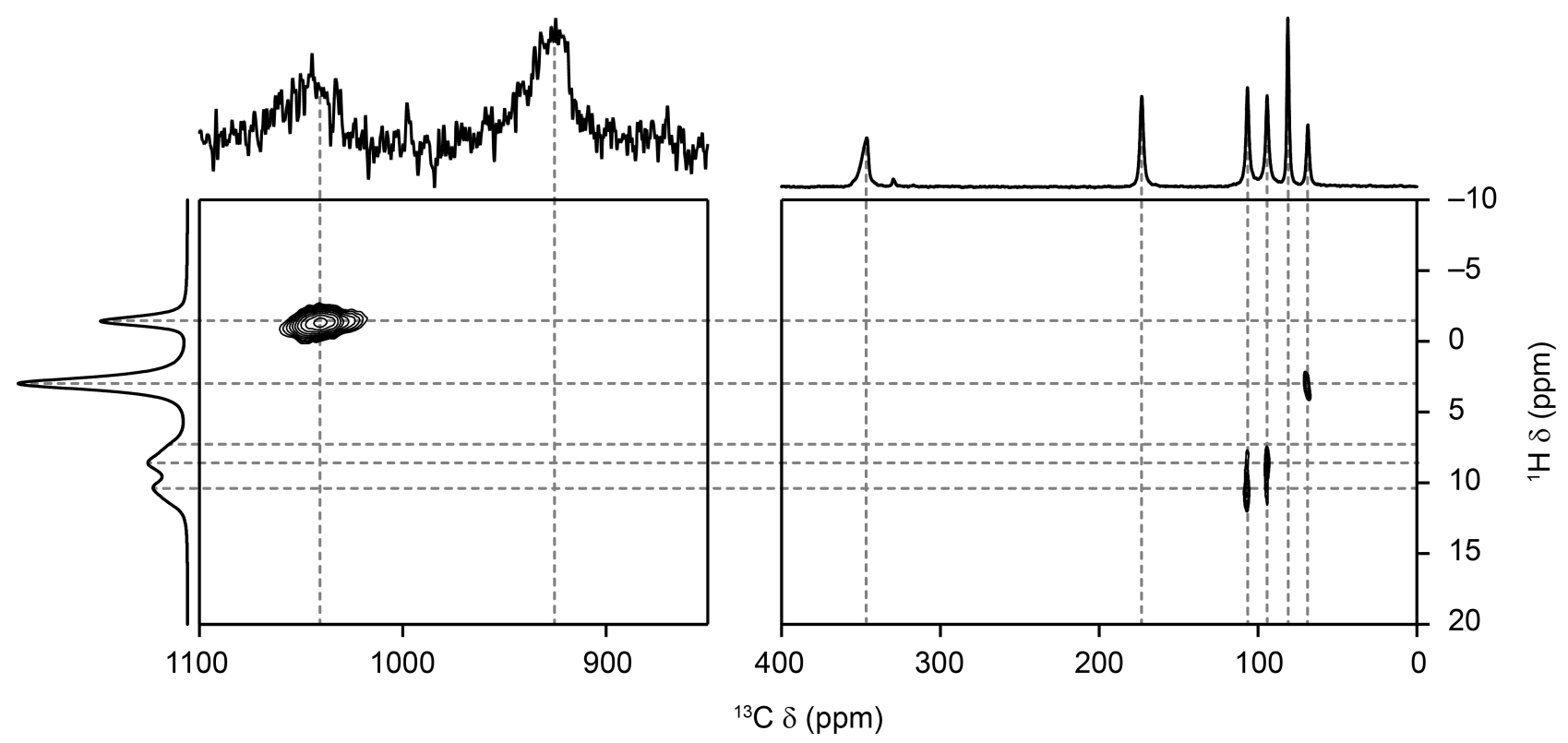

Fig. S4.10. ${ }^{1} \mathrm{H}-{ }^{13} \mathrm{C}(14.1 \mathrm{~T}, 298 \mathrm{~K}, 37.5 \mathrm{kHz}$ MAS) CP HETCOR spectrum of 7.

Fig. S4.11 shows the ${ }^{1} \mathrm{H}$ and ${ }^{13} \mathrm{C}$ MAS NMR spectra of 8. Fig. S4.12 shows the ${ }^{1} \mathrm{H}-{ }^{13} \mathrm{C} \mathrm{CP}$ HETCOR spectrum of 8 .
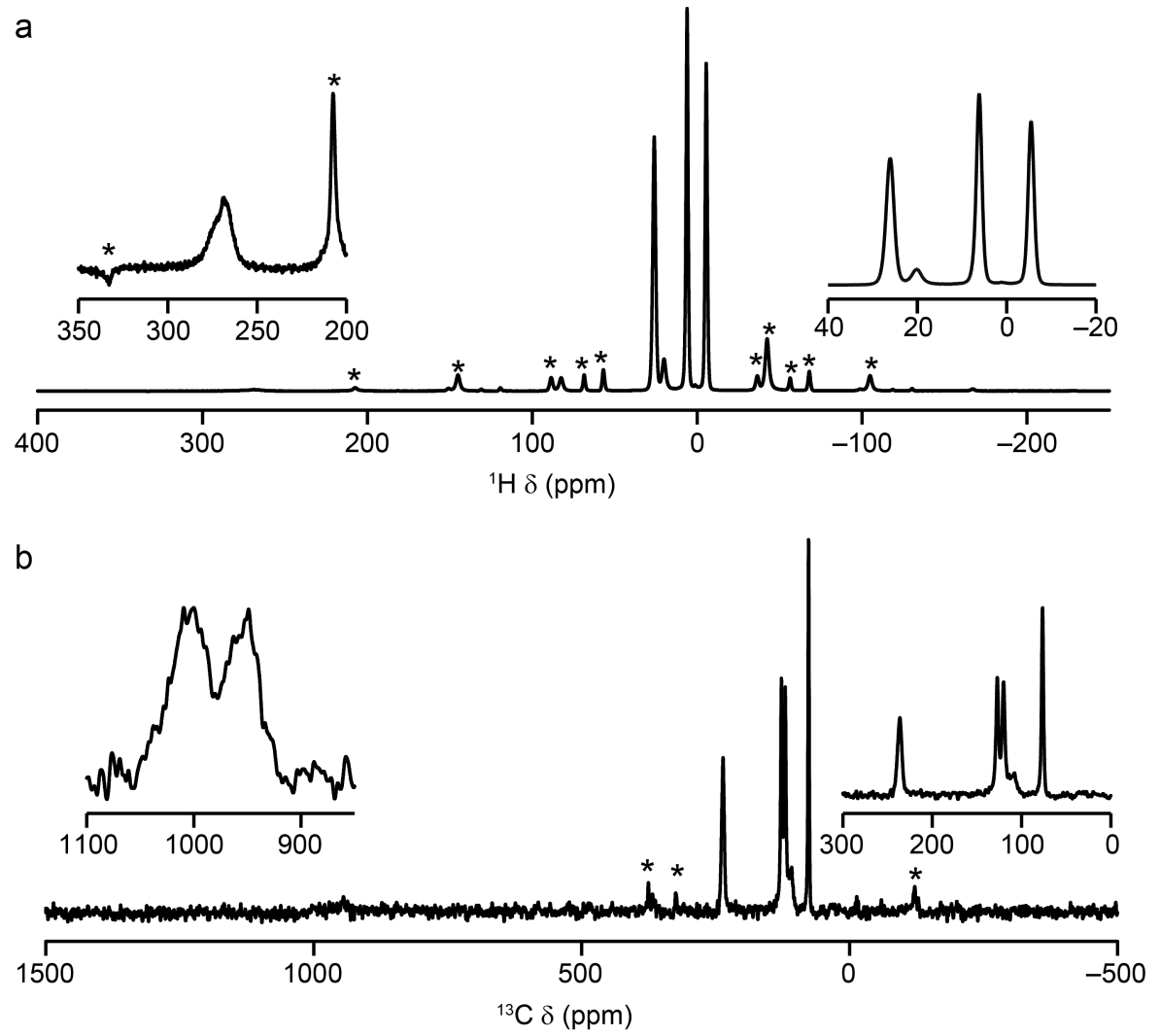

Fig. S4.11. (a) ${ }^{1} \mathrm{H}\left(14.1 \mathrm{~T}, 298 \mathrm{~K}, 37.5 \mathrm{kHz}\right.$ MAS) and (b) ${ }^{13} \mathrm{C}(14.1 \mathrm{~T}, 298 \mathrm{~K}, 37.5 \mathrm{kHz}$ MAS) NMR spectra of 8. Insets show expansions of the most shifted and more closely-spaced resonances. Spinning sidebands are marked by asterisks. 


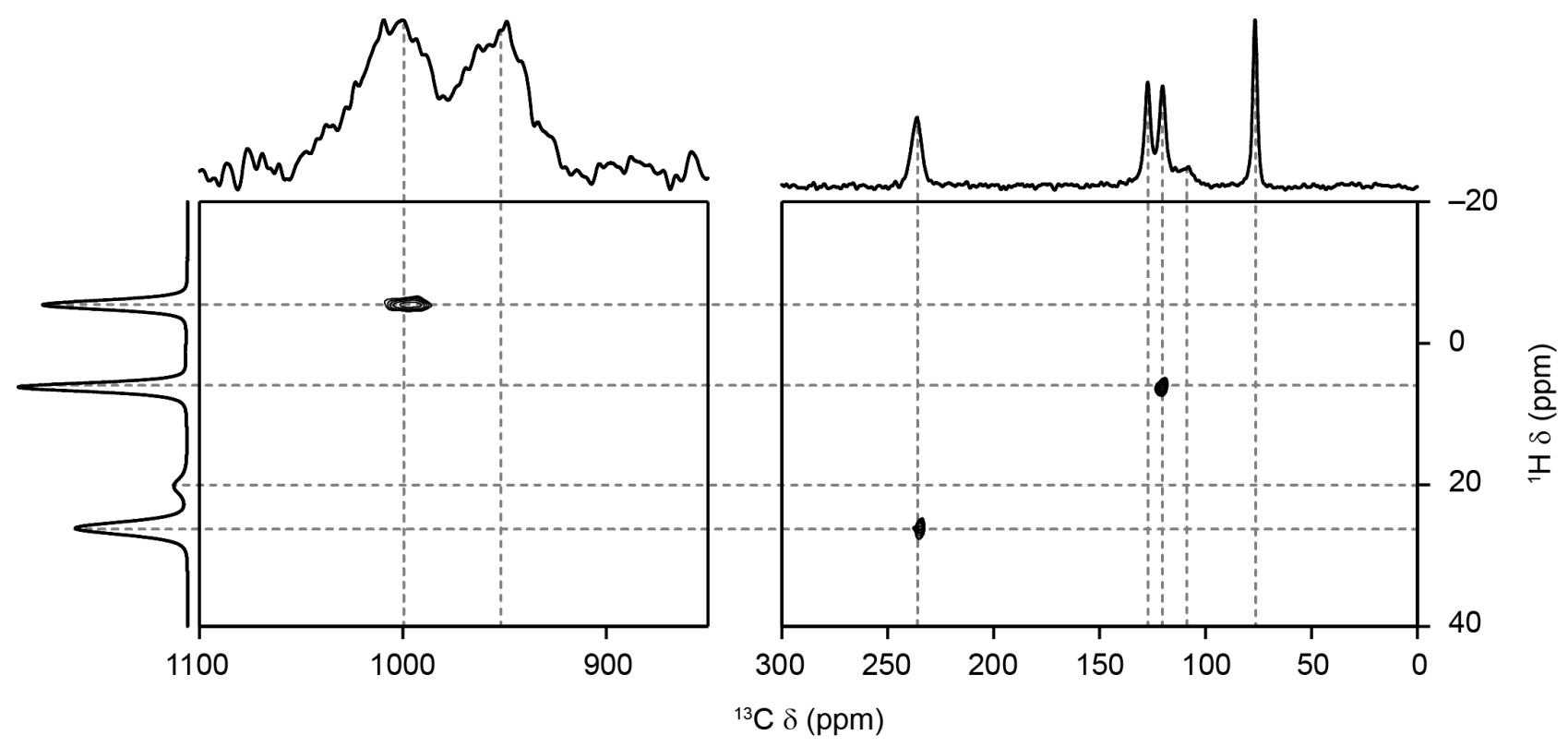

Fig. S4.12. ${ }^{1} \mathrm{H}-{ }^{13} \mathrm{C}(14.1 \mathrm{~T}, 298 \mathrm{~K}, 37.5 \mathrm{kHz}$ MAS) CP HETCOR spectrum of 8.

Fig. S4.13 shows the ${ }^{1} \mathrm{H}$ and ${ }^{13} \mathrm{C}$ MAS NMR spectra of 9. Fig. S4.14 shows the ${ }^{1} \mathrm{H}-{ }^{13} \mathrm{C} \mathrm{CP}$ HETCOR spectrum of 9.
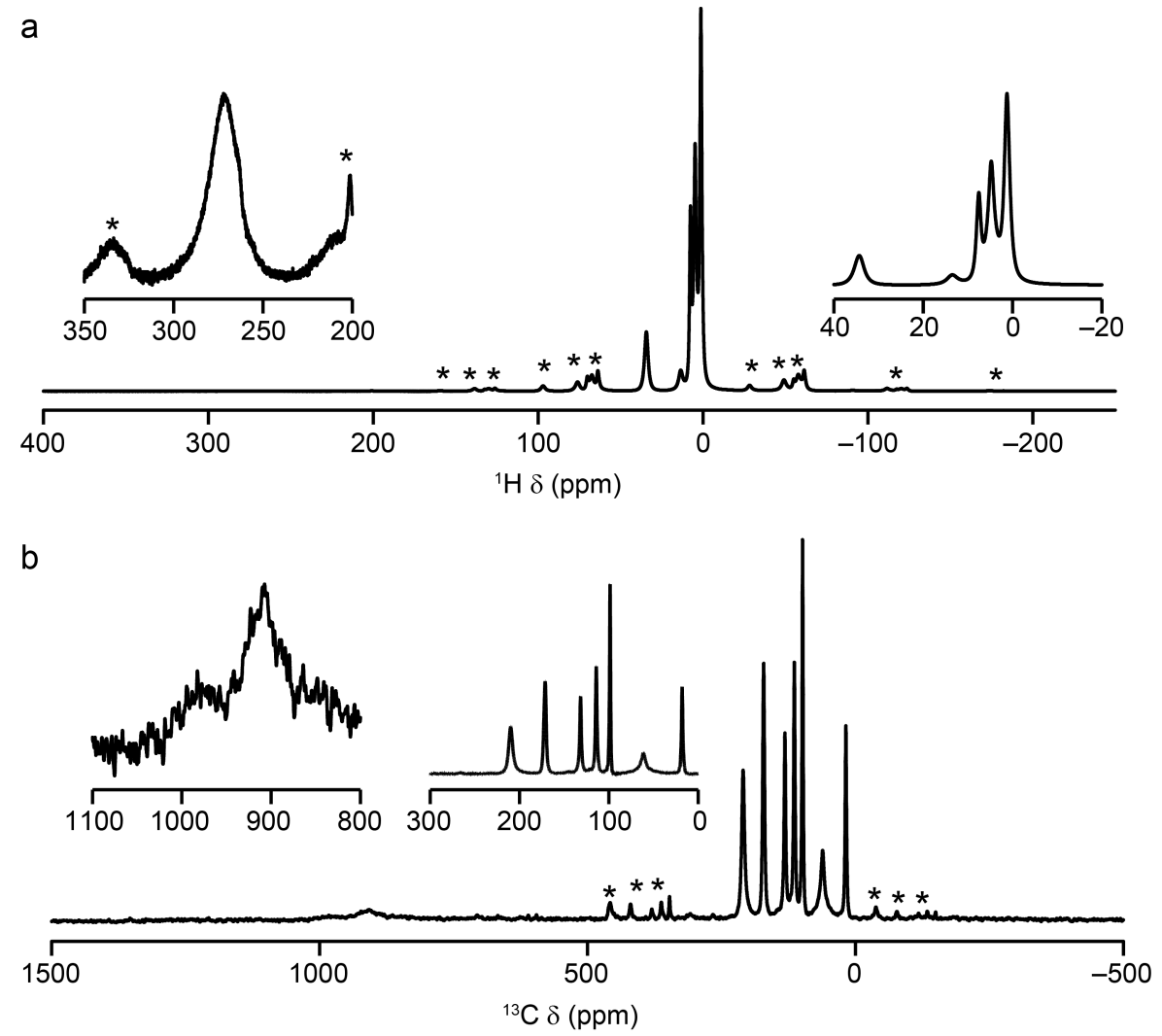

Fig. S4.13. (a) ${ }^{1} \mathrm{H}\left(14.1 \mathrm{~T}, 298 \mathrm{~K}, 37.5 \mathrm{kHz}\right.$ MAS) and (b) ${ }^{13} \mathrm{C}(14.1 \mathrm{~T}, 298 \mathrm{~K}, 37.5 \mathrm{kHz}$ MAS) NMR spectra of 9. Insets show expansions of the most shifted and more closely-spaced resonances. Spinning sidebands are marked by asterisks. 


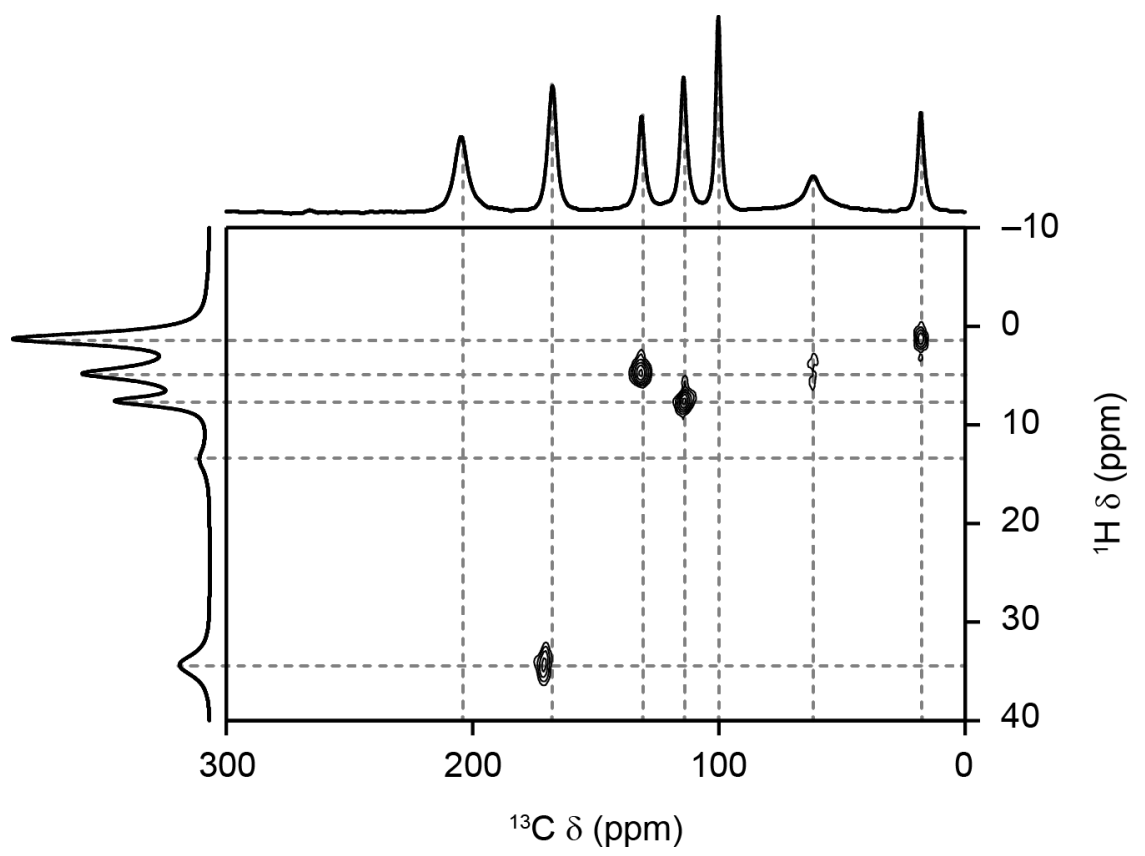

Fig. S4.14. ${ }^{1} \mathrm{H}_{-}{ }^{13} \mathrm{C}(14.1 \mathrm{~T}, 298 \mathrm{~K}, 37.5 \mathrm{kHz}$ MAS) CP HETCOR spectrum of 9. 


\section{S5. Final Assignments of ${ }^{1} \mathrm{H}$ and ${ }^{13} \mathrm{C}$ NMR Spectra of 1-9.}

The following tables report the experimental (exp.) and calculated (DFT) pNMR parameters for 1-5 and 7-9 (see Table 1 of the main text for the equivalent values for 6). Resonances were assigned by achieving the best overall agreement between experimental and calculated values, taking into account connectivity information from the CP HETCOR spectra, as described in the main text. The standard error in the linear regression of a plot of $\delta_{\text {iso }}$ against $1 / \mathrm{T}$ is quoted in parentheses.

Table S5.1. pNMR parameters (as defined in the main text) for $\mathbf{1 .}^{\mathrm{S1}}$

\begin{tabular}{ccccccc}
\hline \multirow{2}{*}{ Species } & \multicolumn{2}{c}{$\delta_{\text {iso }}$ at $298 \mathrm{~K}(\mathrm{ppm})$} & \multicolumn{2}{c}{$\mathrm{d} \delta_{\text {iso }} / \mathrm{d}(1 / \mathrm{T}) / \mathrm{ppm} \mathrm{K}$} & \multicolumn{2}{c}{$\delta_{\text {iso }}(\mathrm{ppm})$} \\
& exp. & $\mathrm{DFT}$ & exp. & DFT & exp. & $\mathrm{DFT}$ \\
\hline $\mathrm{H} 3$ & $-5.4(1)$ & -6.81 & $-3.03(2) \times 10^{3}$ & $-4.11 \times 10^{3}$ & $4.76(5)$ & 6.98 \\
$\mathrm{H} 4$ & $26.0(1)$ & 26.0 & $6.3(3) \times 10^{3}$ & $8.21 \times 10^{3}$ & $4.8(8)$ & 7.47 \\
$\mathrm{H} 5^{\mathrm{a}}$ & $5.5(1)$ & 6.52 & $1.6(3) \times 10^{2}$ & -86.7 & $4.95(9)$ & 6.81 \\
$\mathrm{H} 6^{\mathrm{a}}$ & $5.5(1)$ & 13.4 & $1.6(3) \times 10^{2}$ & $1.85 \times 10^{2}$ & $4.95(9)$ & 7.20 \\
$\mathrm{H} 7$ & $272(2)$ & 306.6 & $8.87(8) \times 10^{4}$ & $8.89 \times 10^{4}$ & $-26(3)$ & 8.30 \\
$\mathrm{Hbr}$ & $22.7(3)$ & 22.7 & $4.24(9) \times 10^{3}$ & $6.30 \times 10^{3}$ & $8.4(3)$ & 10.59 \\
$\mathrm{C} 1$ & $148(1)$ & 132.2 & $3.0(1) \times 10^{3}$ & $3.88 \times 10^{3}$ & $137.4(4)$ & 119.2 \\
$\mathrm{C} 2$ & $79.0(5)$ & 79.4 & $-1.403(3) \times 10^{4}$ & $-2.66 \times 10^{4}$ & $126.1(1)$ & 168.4 \\
$\mathrm{C} 3$ & $1006(5)$ & 1167 & $3.4(2) \times 10^{5}$ & $3.10 \times 10^{5}$ & $-115(51)$ & 126.9 \\
$\mathrm{C} 4$ & $244(1)$ & 235.2 & $3.89(4) \times 10^{4}$ & $2.82 \times 10^{4}$ & $114(1)$ & 140.5 \\
$\mathrm{C} 5^{\mathrm{b}}$ & $124(1)$ & 144.7 & $-8.6(6) \times 10^{2}$ & $7.11 \times 10^{3}$ & $126.9(2)$ & 120.9 \\
$\mathrm{C} 6^{\mathrm{b}}$ & $118(1)$ & 108.7 & $-1.33(5) \times 10^{3}$ & $-9.22 \times 10^{3}$ & $122.3(1)$ & 139.6 \\
$\mathrm{C} 7$ & $963(5)$ & 931.5 & $2.6(3) \times 10^{5}$ & $2.30 \times 10^{5}$ & $90(84)$ & 159.1 \\
\hline
\end{tabular}

a. H5 and H6 are not experimentally distinct, but have different calculated pNMR parameters.

b. C5 and C6 could not be assigned in our earlier work ${ }^{\mathrm{S1}}$ and the assignment may be reversed. 
Table S5.2. pNMR parameters (as defined in the main text) for 2.

\begin{tabular}{ccccccc}
\hline \multirow{2}{*}{ Species } & \multicolumn{2}{c}{$\delta_{\text {iso }}$ at $298 \mathrm{~K}(\mathrm{ppm})$} & \multicolumn{2}{c}{$\mathrm{d} \delta_{\text {iso }} / \mathrm{d}(1 / \mathrm{T}) / \mathrm{ppm} \mathrm{K}$} & \multicolumn{2}{c}{$\delta_{\text {iso }}(\mathrm{ppm})$} \\
& exp. & $\mathrm{DFT}$ & $\mathrm{exp}$. & $\mathrm{DFT}$ & $\mathrm{exp}$. & $\mathrm{DFT}$ \\
\hline $\mathrm{H} 3$ & -1.8 & -3.7 & $-2.40(4) \times 10^{3}$ & $-3.19 \times 10^{3}$ & $6.3(1)$ & 7.00 \\
$\mathrm{H} 4$ & 28.6 & 35.2 & $5.85(4) \times 10^{3}$ & $8.29 \times 10^{3}$ & $9.0(1)$ & 7.41 \\
$\mathrm{H} 5$ & 5.2 & 6.7 & $1.4(3) \times 10^{2}$ & -27.7 & $4.8(1)$ & 6.81 \\
$\mathrm{H} 6$ & 10.7 & 15.1 & $1.26(1) \times 10^{3}$ & $2.24 \times 10^{3}$ & $6.48(5)$ & 7.60 \\
$\mathrm{H} 8$ & -14.9 & -29.0 & $-5.33(5) \times 10^{3}$ & $-9.38 \times 10^{3}$ & $3.0(2)$ & 2.50 \\
$\mathrm{Hbr}$ & 31.7 & 28.3 & $6.3(1) \times 10^{3}$ & $5.03 \times 10^{3}$ & $10.5(3)$ & 11.40 \\
$\mathrm{C} 1$ & 110 & 120.1 & $-5.31(5) \times 10^{3}$ & $-2.96 \times 10^{2}$ & $127.4(2)$ & 121.1 \\
$\mathrm{C} 2$ & 81 & 84.5 & $-1.18(2) \times 10^{4}$ & $-2.46 \times 10^{4}$ & $120.4(8)$ & 167.2 \\
C3 & - & 1146 & - & $3.04 \times 10^{5}$ & - & 127.2 \\
C4 & 248 & 270.4 & $3.25(7) \times 10^{4}$ & $3.91 \times 10^{4}$ & $138(2)$ & 139.1 \\
C5 & 133 & 136.6 & $3.211(6) \times 10^{3}$ & $4.78 \times 10^{3}$ & $122.07(2)$ & 120.6 \\
C6 & 76 & 77.3 & $-1.3(1) \times 10^{4}$ & $-1.74 \times 10^{4}$ & $118(4)$ & 135.6 \\
C7 & - & 951.7 & - & $2.34 \times 10^{5}$ & - & 166.1 \\
C8 & 284 & 459.0 & $4.56(3) \times 10^{4}$ & $1.33 \times 10^{5}$ & $131(1)$ & 13.6 \\
\hline
\end{tabular}

a. not observed experimentally, perhaps owing to very rapid $\mathrm{T}_{1}$ relaxation. 
Table S5.3. pNMR parameters (as defined in the main text) for 3 . Where multiple resonances are observed for one chemical species, these are denoted '. The complex has $C_{2}$ symmetry in the gas-phase calculation, so no such inequivalences are predicted by DFT.

\begin{tabular}{|c|c|c|c|c|c|c|}
\hline \multirow{2}{*}{ Species } & \multicolumn{2}{|c|}{$\delta_{\text {iso }}$ at $298 \mathrm{~K}(\mathrm{ppm})$} & \multicolumn{2}{|c|}{$\mathrm{d} \delta_{\text {iso }} / \mathrm{d}(1 / \mathrm{T}) / \mathrm{ppm} \mathrm{K}$} & \multicolumn{2}{|c|}{$\delta_{\text {iso }}^{\infty}(\mathrm{ppm})$} \\
\hline & exp. & DFT & exp. & DFT & exp. & DFT \\
\hline $\mathrm{H} 3$ & -5.3 & -8.2 & $-2.63(6) \times 10^{3}$ & $-4.59 \times 10^{3}$ & $3.5(2)$ & 7.20 \\
\hline $\mathrm{H} 3^{\prime}$ & -5.8 & -8.2 & $-3.02(6) \times 10^{3}$ & $-4.59 \times 10^{3}$ & $4.4(2)$ & 7.20 \\
\hline $\mathrm{H} 4$ & 35.9 & 43.0 & $8.2(2) \times 10^{3}$ & $1.05 \times 10^{4}$ & $8.3(8)$ & 7.95 \\
\hline $\mathrm{H} 4^{\prime}$ & 33.6 & 43.0 & $7.9(2) \times 10^{3}$ & $1.05 \times 10^{4}$ & $7.0(7)$ & 7.95 \\
\hline $\mathrm{H} 7$ & 277 & 303.7 & $7.9(1) \times 10^{4}$ & $8.77 \times 10^{4}$ & $12(3)$ & 9.52 \\
\hline $\mathrm{H}^{\prime}$ & 268 & 303.7 & $7.5(1) \times 10^{4}$ & $8.77 \times 10^{4}$ & $13(4)$ & 9.52 \\
\hline $\mathrm{H} 8$ & 7.5 & 9.5 & $266(7)$ & 470 & $6.61(2)$ & 7.88 \\
\hline H9 & 6.45 & 7.0 & 199(8) & -142 & $5.79(3)$ & 7.48 \\
\hline H10 & 10.2 & 10.5 & $8.1(2) \times 10^{2}$ & 830 & $7.49(7)$ & 7.72 \\
\hline H11 & 6.5 & 8.0 & $269(8)$ & -48 & $5.60(3)$ & 8.16 \\
\hline $\mathrm{H} 11^{\prime}$ & 4.9 & 8.0 & $-37(11)$ & -48 & $5.02(4)$ & 8.16 \\
\hline $\mathrm{Hbr}$ & 12.3 & 33.5 & $5.7(8) \times 10^{2}$ & $6.96 \times 10^{3}$ & $10.5(3)$ & 10.17 \\
\hline $\mathrm{C} 1$ & 90 & 122.5 & $-6.09(8) \times 10^{3}$ & $4.11 \times 10^{3}$ & $110.6(3)$ & 108.7 \\
\hline $\mathrm{C} 2$ & 107 & 138.1 & $-6.18(4) \times 10^{3}$ & $-9.42 \times 10^{3}$ & $127.8(1)$ & 169.7 \\
\hline $\mathrm{C} 2^{\prime}$ & 103 & 138.2 & $-7.52(6) \times 10^{3}$ & $-9.42 \times 10^{3}$ & $127.8(2)$ & 169.7 \\
\hline $\mathrm{C} 3$ & 1055 & 1209 & $2.70(2) \times 10^{5}$ & $3.22 \times 10^{5}$ & 151(7) & 129.3 \\
\hline $\mathrm{C} 4$ & 279 & 266.7 & $4.29(2) \times 10^{4}$ & $3.71 \times 10^{4}$ & $135.1(7)$ & 142.2 \\
\hline C5 & 169 & 156.0 & $8.14(5) \times 10^{3}$ & $7.35 \times 10^{3}$ & $142.0(2)$ & 131.4 \\
\hline C6 & 74 & 86.0 & $-1.22(1) \times 10^{4}$ & $-1.58 \times 10^{4}$ & $114.9(4)$ & 138.8 \\
\hline $\mathrm{C} 7$ & 1003 & 932.3 & $2.53(2) \times 10^{5}$ & $2.32 \times 10^{5}$ & 151(7) & 154.6 \\
\hline $\mathrm{C} 8$ & 124 & 127.4 & $-1.12(9) \times 10^{3}$ & $-2.48 \times 10^{3}$ & $127.5(3)$ & 135.7 \\
\hline C9 & 132 & 142.4 & $1.0(3) \times 10^{2}$ & $4.39 \times 10^{3}$ & $132.0(1)$ & 127.7 \\
\hline$C 9^{\prime}$ & 128.2 & 142.4 & $-7.5(5) \times 10^{2}$ & $4.39 \times 10^{3}$ & $130.7(2)$ & 127.7 \\
\hline $\mathrm{C} 10$ & 129 & 120.4 & $2.5(3) \times 10^{3}$ & $-4.06 \times 10^{3}$ & 121(1) & 134.1 \\
\hline $\mathrm{C} 10^{\prime}$ & 128.1 & 120.4 & $1.7(8) \times 10^{3}$ & $-4.06 \times 10^{3}$ & $122(3)$ & 134.1 \\
\hline $\mathrm{C} 11$ & 121 & 142.4 & $-1.5(1) \times 10^{3}$ & $5.57 \times 10^{3}$ & $126.2(3)$ & 123.7 \\
\hline
\end{tabular}


Table S5.4. pNMR parameters (as defined in the main text) for 4 .

\begin{tabular}{ccccccc}
\hline \multirow{2}{*}{ Species } & \multicolumn{2}{c}{$\delta_{\text {iso }}$ at $298 \mathrm{~K}(\mathrm{ppm})$} & \multicolumn{2}{c}{$\mathrm{d} \delta_{\text {iso }} / \mathrm{d}(1 / \mathrm{T}) / \mathrm{ppm} \mathrm{K}$} & \multicolumn{2}{c}{$\delta_{\text {iso }}{ }^{\circ}(\mathrm{ppm})$} \\
& exp. & $\mathrm{DFT}$ & $\mathrm{exp}$. & $\mathrm{DFT}$ & $\mathrm{exp}$. & $\mathrm{DFT}$ \\
\hline $\mathrm{H} 4$ & 36.6 & 40.2 & $9.25(8) \times 10^{3}$ & $9.96 \times 10^{3}$ & $5.6(3)$ & 6.76 \\
$\mathrm{H} 5$ & 8.1 & 5.0 & $4.3(2) \times 10^{2}$ & -513 & $6.67(7)$ & 6.74 \\
$\mathrm{H} 6$ & 5.4 & 12.3 & $1.1(4) \times 10^{2}$ & $1.64 \times 10^{3}$ & $5.0(1)$ & 6.81 \\
$\mathrm{H} 7$ & 276 & 309 & $7.9(3) \times 10^{4}$ & $8.96 \times 10^{4}$ & $12(10)$ & 8.16 \\
$\mathrm{H} 8$ & 4.3 & 4.0 & $141(6)$ & $8.77 \times 10^{4}$ & $3.78(2)$ & 3.61 \\
$\mathrm{Hbr}$ & 9.4 & 32.0 & $-8.1(2) \times 10^{2}$ & $6.33 \times 10^{3}$ & $12.16(7)$ & 10.79 \\
$\mathrm{C} 1$ & 95 & 131.1 & $-7.95(8) \times 10^{3}$ & $3.61 \times 10^{3}$ & $121.4(3)$ & 119.0 \\
$\mathrm{C} 2$ & 210 & 175.9 & $2.42(1) \times 10^{4}$ & $5.13 \times 10^{3}$ & $128.4(3)$ & 158.7 \\
$\mathrm{C} 3$ & 922 & 1060 & $2.1(1) \times 10^{5}$ & $2.69 \times 10^{5}$ & $211(31)$ & 156.8 \\
$\mathrm{C} 4$ & 167 & 163.7 & $1.639(5) \times 10^{4}$ & $1.42 \times 10^{4}$ & $110.0(2)$ & 116.0 \\
$\mathrm{C} 5$ & 121 & 149.2 & $1.31(6) \times 10^{3}$ & $8.74 \times 10^{3}$ & $116.1(2)$ & 119.9 \\
$\mathrm{C} 6$ & 132 & 99.8 & $2.58(7) \times 10^{3}$ & $-8.84 \times 10^{3}$ & $123.0(2)$ & 129.5 \\
$\mathrm{C} 7$ & 944 & 920 & $2.47(6) \times 10^{5}$ & $2.27 \times 10^{5}$ & $116(21)$ & 158.1 \\
$\mathrm{C} 8$ & 58 & 47.3 & $-2.0(4) \times 10^{2}$ & $2.23 \times 10^{3}$ & $59.0(1)$ & 54.8 \\
\hline
\end{tabular}


Table S5.5. pNMR parameters (as defined in the main text) for 5. Where multiple resonances are observed for one chemical species, these are denoted '. The complex has $C_{2}$ symmetry in the gas-phase calculation, so no such inequivalences are predicted by DFT.

\begin{tabular}{ccccccc}
\hline \multirow{2}{*}{ Species } & $\delta_{\text {iso }}$ at $298 \mathrm{~K}(\mathrm{ppm})$ & \multicolumn{2}{c}{$\mathrm{d} \delta_{\text {iso }} / \mathrm{d}(1 / \mathrm{T}) / \mathrm{ppm} \mathrm{K}$} & \multicolumn{2}{c}{$\delta_{\text {iso }}(\mathrm{ppm})$} \\
& exp. & $\mathrm{DFT}$ & $\mathrm{exp}$ & $\mathrm{DFT}$ & $\mathrm{exp}$. & $\mathrm{DFT}$ \\
\hline $\mathrm{H} 3$ & -6.0 & -6.9 & $-3.29(4) \times 10^{3}$ & $-4.14 \times 10^{3}$ & $5.0(1)$ & 6.95 \\
$\mathrm{H} 4$ & 30.0 & 35.4 & $6.81(7) \times 10^{3}$ & $8.23 \times 10^{3}$ & $7.2(2)$ & 7.58 \\
$\mathrm{H} 6$ & 10.7 & 13.4 & $7.9(2) \times 10^{2}$ & $1.88 \times 10^{3}$ & $12.6(1)$ & 7.13 \\
$\mathrm{H} 7$ & 271 & 306 & $6.8(2) \times 10^{4}$ & $8.87 \times 10^{4}$ & $43(7)$ & 8.12 \\
$\mathrm{H} 9$ & 2.0 & 1.2 & $207(9)$ & -19.5 & $1.29(3)$ & 1.24 \\
H9' & 1.9 & 1.2 & $1.8(3) \times 10^{2}$ & -19.5 & $1.22(9)$ & 1.24 \\
Hbr & 7.5 & 31.1 & $3.0(1) \times 10^{2}$ & $6.12 \times 10^{3}$ & $6.51(3)$ & 10.56 \\
C1 & 107 & 131.0 & $-8.0(2) \times 10^{3}$ & $3.93 \times 10^{3}$ & $134.0(5)$ & 117.8 \\
C2 & 94 & 77.1 & $-8.43(9) \times 10^{3}$ & $-2.67 \times 10^{4}$ & $122.5(3)$ & 166.8 \\
C2' & 91 & 77.1 & $-8.9(1) \times 10^{3}$ & $-2.67 \times 10^{4}$ & $121.0(3)$ & 166.8 \\
C3 & 1326 & 1070 & $7(2) \times 10^{5}$ & $3.11 \times 10^{5}$ & $-1020(790)$ & 126.1 \\
C4 & 233 & 231.7 & $3.03(4) \times 10^{4}$ & $2.75 \times 10^{4}$ & $131(1)$ & 139.4 \\
C5 & 149 & 168.6 & $7.2(3) \times 10^{2}$ & $7.53 \times 10^{3}$ & $146.92(9)$ & 143.3 \\
C6 & 117 & 101.0 & $-9.2(5) \times 10^{2}$ & $-1.00 \times 10^{4}$ & $120.2(2)$ & 134.7 \\
C6' & 115 & 101.0 & $-3.4(1) \times 10^{3}$ & $-1.00 \times 10^{4}$ & $126.6(3)$ & 134.7 \\
C7 & 1013 & 937 & $2.4(3) \times 10^{5}$ & $2.32 \times 10^{5}$ & $186(93)$ & 158.9 \\
C8 & 37 & 35.4 & $1.13(1) \times 10^{3}$ & -65.8 & $33.08(4)$ & 35.6 \\
C9 & 35 & 34.1 & $-3.5(3) \times 10^{2}$ & 450 & $36.01(9)$ & 32.6 \\
\hline
\end{tabular}


Table S5.6. pNMR parameters (as defined in the main text) for 7.

\begin{tabular}{ccccccc}
\hline \multirow{2}{*}{ Species } & \multicolumn{2}{c}{$\delta_{\text {iso }}$ at $298 \mathrm{~K}(\mathrm{ppm})$} & \multicolumn{2}{c}{$\mathrm{d} \delta_{\text {iso }} / \mathrm{d}(1 / \mathrm{T}) / \mathrm{ppm} \mathrm{K}$} & \multicolumn{2}{c}{$\delta_{\text {iso }}(\mathrm{ppm})$} \\
& exp. & $\mathrm{DFT}$ & $\mathrm{exp}$. & $\mathrm{DFT}$ & exp. & $\mathrm{DFT}$ \\
\hline $\mathrm{H} 3$ & -1.4 & -2.7 & $-1.94(1) \times 10^{3}$ & $-2.67 \times 10^{3}$ & $5.12(4)$ & 6.22 \\
$\mathrm{H} 5$ & 8.7 & 5.7 & $8.4(2) \times 10^{2}$ & -235 & $5.84(6)$ & 6.46 \\
$\mathrm{H} 6$ & 10.5 & 11.1 & $1.17(7) \times 10^{3}$ & $1.22 \times 10^{3}$ & $6.5(2)$ & 7.03 \\
$\mathrm{H} 7$ & 274 & 302 & $8.1(1) \times 10^{4}$ & $8.76 \times 10^{4}$ & $2(3)$ & 7.99 \\
$\mathrm{H} 8$ & 3.0 & 2.2 & $-1.5(1) \times 10^{2}$ & -403 & $3.54(5)$ & 3.58 \\
$\mathrm{Hbr}$ & 7.7 & 32.5 & $6.6(2) \times 10^{2}$ & $6.65 \times 10^{3}$ & $5.5(5)$ & 10.19 \\
$\mathrm{C} 1$ & 173 & 112.5 & $1.065(8) \times 10^{4}$ & 102 & $137.6(3)$ & 112.2 \\
$\mathrm{C} 2$ & 81 & 143.8 & $-9.90(6) \times 10^{3}$ & $-8.06 \times 10^{3}$ & $114.6(2)$ & 170.8 \\
$\mathrm{C} 3$ & 1047 & 1209 & $2.84(8) \times 10^{5}$ & $3.29 \times 10^{5}$ & $95(25)$ & 104.7 \\
$\mathrm{C} 4$ & 347 & 329.6 & $5.74(5) \times 10^{4}$ & $4.74 \times 10^{4}$ & $155(2)$ & 170.5 \\
$\mathrm{C} 5$ & 94 & 127.8 & $-4.80(8) \times 10^{3}$ & $4.71 \times 10^{3}$ & $110.5(3)$ & 112.1 \\
$\mathrm{C} 6$ & 107 & 102.2 & $-7.17(6) \times 10^{3}$ & $-1.14 \times 10^{4}$ & $130.8(2)$ & 140.6 \\
$\mathrm{C} 7$ & 928 & 928 & $2.41(5) \times 10^{5}$ & $2.29 \times 10^{5}$ & $119(16)$ & 157.8 \\
$\mathrm{C} 8$ & 69 & 61.4 & $4.40(6) \times 10^{3}$ & $1.96 \times 10^{3}$ & $54.0(2)$ & 54.8 \\
\hline
\end{tabular}

Table S5.7. pNMR parameters (as defined in the main text) for 8 .

\begin{tabular}{|c|c|c|c|c|c|c|}
\hline \multirow{2}{*}{ Species } & \multicolumn{2}{|c|}{$\delta_{\text {iso }}$ at $298 \mathrm{~K}(\mathrm{ppm})$} & \multicolumn{2}{|c|}{$\mathrm{d} \delta_{\text {iso }} / \mathrm{d}(1 / \mathrm{T}) / \mathrm{ppm} \mathrm{K}$} & \multicolumn{2}{|c|}{$\delta_{\text {iso }}^{\infty}(\mathrm{ppm})$} \\
\hline & exp. & DFT & exp. & DFT & exp. & DFT \\
\hline H3 & -5.4 & -6.8 & $-2.71(5) \times 10^{3}$ & $-4.09 \times 10^{3}$ & $3.7(2)$ & 6.88 \\
\hline $\mathrm{H} 4$ & 26.1 & 34.0 & $5.24(5) \times 10^{3}$ & $7.92 \times 10^{3}$ & $8.5(1)$ & 7.46 \\
\hline H6 & 6.2 & 14.4 & $1.2(2) \times 10^{2}$ & $2.15 \times 10^{3}$ & $5.82(8)$ & 7.23 \\
\hline $\mathrm{H} 7$ & 269 & 308.4 & $7.7(5) \times 10^{4}$ & $8.95 \times 10^{4}$ & $13(17)$ & 8.06 \\
\hline $\mathrm{Hbr}$ & 20.2 & 32.4 & $2.24(3) \times 10^{3}$ & $6.54 \times 10^{3}$ & $12.6(1)$ & 10.49 \\
\hline $\mathrm{C} 1$ & 127 & 129.1 & $-4.2(1) \times 10^{3}$ & $2.62 \times 10^{3}$ & $141.5(4)$ & 120.3 \\
\hline $\mathrm{C} 2$ & 77 & 83.4 & $-1.23(2) \times 10^{4}$ & $-2.49 \times 10^{4}$ & $118.0(6)$ & 167.1 \\
\hline $\mathrm{C} 3$ & 1005 & 1178 & $2.55(5) \times 10^{5}$ & $3.13 \times 10^{5}$ & $148(15)$ & 127.3 \\
\hline $\mathrm{C} 4$ & 236 & 234.6 & $2.96(5) \times 10^{4}$ & $2.70 \times 10^{4}$ & $137(2)$ & 143.8 \\
\hline C5 & 109 & 153.4 & $-3.2(7) \times 10^{3}$ & $7.70 \times 10^{3}$ & $120(2)$ & 127.5 \\
\hline C6 & 120 & 100.9 & $-2.53(8) \times 10^{3}$ & $-1.23 \times 10^{4}$ & $128.8(2)$ & 142.2 \\
\hline $\mathrm{C} 7$ & 951 & 895 & $2.41(2) \times 10^{5}$ & $2.20 \times 10^{5}$ & 143(7) & 158.2 \\
\hline
\end{tabular}


Table S5.8. pNMR parameters (as defined in the main text) for 9.

\begin{tabular}{ccccccc}
\hline \multirow{2}{*}{ Species } & \multicolumn{2}{c}{$\delta_{\text {iso }}$ at $298 \mathrm{~K}(\mathrm{ppm})$} & \multicolumn{2}{c}{$\mathrm{d} \delta_{\text {iso }} / \mathrm{d}(1 / \mathrm{T}) / \mathrm{ppm} \mathrm{K}$} & \multicolumn{2}{c}{$\left.\delta_{\text {iso }}{ }^{\circ} \mathrm{ppm}\right)$} \\
& exp. & $\mathrm{DFT}$ & $\mathrm{exp}$. & $\mathrm{DFT}$ & $\mathrm{exp}$. & $\mathrm{DFT}$ \\
\hline $\mathrm{H} 4$ & 34.4 & 40.0 & $8.1(1) \times 10^{3}$ & $9.92 \times 10^{3}$ & $7.2(4)$ & 6.74 \\
$\mathrm{H} 5$ & 4.8 & 4.9 & $1.5(2) \times 10^{2}$ & -534 & $4.28(7)$ & 6.72 \\
$\mathrm{H} 6$ & 7.6 & 12.3 & $2.9(1) \times 10^{2}$ & $1.65 \times 10^{3}$ & $6.62(5)$ & 6.79 \\
$\mathrm{H} 7$ & 272 & 309 & $7.9(3) \times 10^{4}$ & $8.95 \times 10^{4}$ & $6(8)$ & 8.17 \\
H8 & 4.8 & 4.3 & $1.5(2) \times 10^{2}$ & 188 & $4.28(7)$ & 3.66 \\
H9 & 1.3 & 1.0 & $-83(26)$ & -117 & $1.55(9)$ & 1.41 \\
Hbr & 13.6 & 31.8 & $189(7)$ & $6.25 \times 10^{3}$ & $12.96(2)$ & 10.86 \\
C1 & 99 & 131.3 & $-6.39(8) \times 10^{3}$ & $3.69 \times 10^{3}$ & $120.4(3)$ & 118.9 \\
C2 & 210 & 175.2 & $2.49(3) \times 10^{4}$ & $5.00 \times 10^{3}$ & $126.5(8)$ & 158.4 \\
C3 & 907 & 1055 & $2.1(1) \times 10^{5}$ & $2.68 \times 10^{5}$ & $195(31)$ & 156.3 \\
C4 & 172 & 163.9 & $1.90(2) \times 10^{4}$ & $1.42 \times 10^{4}$ & $107.9(5)$ & 116.4 \\
C5 & 132 & 149.7 & $2.1(1) \times 10^{3}$ & $8.88 \times 10^{3}$ & $124.8(4)$ & 119.9 \\
C6 & 114 & 98.9 & $-3.0(8) \times 10^{2}$ & $-9.04 \times 10^{3}$ & $115.4(3)$ & 129.2 \\
C7 & 980 & 919 & $2.4(1) \times 10^{5}$ & $2.27 \times 10^{5}$ & $187(37)$ & 158.1 \\
C8 & 62 & 56.8 & $-1(3) \times 10^{3}$ & $-2.13 \times 10^{3}$ & $64.8(9)$ & 63.9 \\
C9 & 18 & 15.1 & $5(1) \times 10^{2}$ & -289 & $16.3(4)$ & 16.1 \\
\hline
\end{tabular}




\section{S6. Vibrational Effects on the pNMR Parameters of 1}

To investigate possible effects of vibrational averaging on the chemical shifts of $\mathbf{1}$ the effective zero-point averaged structure $\left(\mathrm{r}_{\mathrm{g}}{ }^{0}\right.$ structure) was computed from the cubic force field using the method of Barone et al. ${ }^{.29}$ The cubic force field was evaluated through numerical differentiation of harmonic second derivatives within Gaussian $09^{513}$ at the same PBE0-D3/Wachters/6-31G $\mathrm{G}^{*(*)}$ level used for structure optimisation (using tight optimisation criteria through the opt=tight option), employing the default values for step size in the numerical differentiation $(0.025 \AA)$ and the integration grid. pNMR shifts were computed for this zero-point averaged structure at the PBE0-1/3/II level (and referenced to TMS, which was vibrationally averaged the same way). This method has been used previously to assess the effects of vibrational averaging on structural and NMR parameters of diamagnetic transition metal complexes. ${ }^{S 30}$ The results are summarised in Table S6.1.

As expected from the increase in $r_{g}{ }^{0}$ over $r_{e}$ bond lengths and the usual tendency towards decreased shielding with increased bond distances, most resonances have a slightly larger shift upon vibrational averaging. Notable exceptions are the strongly deshielded C3 and C7 resonances, which become more shielded (by up to 3 ppm), and $\mathrm{Hbr}$, which is $2.5 \mathrm{ppm}$ more shielded. The latter change is quite substantial for a ${ }^{1} \mathrm{H}$ shift and could point to a strongly anharmonic stretching potential of the corresponding bond, which would not be unusual for protons involved in strong, possibly low-barrier hydrogen bonds. Inspection of the vibrationally averaged $\mathrm{OH}$ distances involved in the intramolecular H-bond, however, shows only minor changes from the optimised equilibrium values (around $0.003 \AA$, see Table S6.2).

When the stretching potential for simultaneous compression and elongation of the two O$\mathrm{Hbr}$ bonds was computed explicitly (through optimising all other parameters at the PBE0D3/Wachters/6-31G**) level in $C_{2 h}$ symmetry), the potential shown in Fig. S6.1 was obtained. It shows the characteristic of a deep single well, where distinct deviations from a 
"normal" Morse-type potential (dotted curve in Fig. S6.1) are only apparent at large OH distances and rather high energies. The notable effect of vibrational averaging on the shift of Hbr (Table S6.1) thus appears to be due to a strong structural sensitivity of this property (rather than large structural changes upon vibrational averaging). This interpretation is consistent with the location of this proton in an area of strongly variable spin density (cf. Fig. $2 b$ of the main text), where relatively small displacements ( $c f$. Table S6.2) can result in relatively large variations of the magnetic shielding and, arguably, of its temperature dependence.

Table S6.1. Computed pNMR chemical shifts ${ }^{a}$ (in ppm relative to TMS) ${ }^{b}$ for $\mathbf{1}$ in its equilibrium $\left(\mathrm{r}_{\mathrm{e}}\right)$ and zero-point averaged structures $\left(\mathrm{r}_{\mathrm{g}}{ }^{0}\right)$.

\begin{tabular}{ccc}
\hline \multirow{2}{*}{ Species } & $\mathrm{r}_{\mathrm{e}}(\mathrm{ppm})$ & $\mathrm{r}_{\mathrm{g}}{ }^{0}$ \\
\hline $\mathrm{H} 3$ & -6.8 & -6.6 \\
$\mathrm{H} 4$ & 35.0 & 35.6 \\
$\mathrm{H} 5$ & 6.5 & 6.9 \\
$\mathrm{H} 6$ & 13.4 & 13.8 \\
$\mathrm{H} 7$ & 306.6 & 308.2 \\
$\mathrm{Hbr}$ & 31.7 & 29.2 \\
$\mathrm{C} 1$ & 132.4 & 134.5 \\
$\mathrm{C} 2$ & 79.2 & 79.9 \\
$\mathrm{C} 3$ & 1166.6 & 1164.7 \\
$\mathrm{C} 4$ & 235.3 & 237.3 \\
$\mathrm{C} 5$ & 144.8 & 147.4 \\
$\mathrm{C} 6$ & 108.8 & 110.7 \\
$\mathrm{C} 7$ & 931.4 & 930.8 \\
\hline
\end{tabular}

a. PBE0-1/3/IGLO-II level, doublet state.

b. Averaged $\sigma_{\text {iso }}$ for TMS: ${ }^{1} \mathrm{H} 31.8 \mathrm{ppm},{ }^{13} \mathrm{C} 189.0 \mathrm{ppm}$ at equilibrium, ${ }^{1} \mathrm{H} 32.14 \mathrm{ppm}$, ${ }^{13} \mathrm{C} 190.88$ ppm at $0 \mathrm{~K}$. 
Table S6.2. Distances (in $\AA$ ) between bridging hydrogen and its neighboring oxygens. ${ }^{a}$

\begin{tabular}{ccc}
\hline Bond & $\mathrm{r}_{\mathrm{e}}$ & $\mathrm{r}_{\mathrm{g}}{ }^{0}$ \\
\hline $\mathrm{O}-\mathrm{Hbr}$ & 0.987 & 0.990 \\
$\mathrm{O} \cdots \mathrm{Hbr}$ & 1.724 & 1.727 \\
\hline
\end{tabular}

a. PBE0-D3/Wachters/6-31G ${ }^{*(*)}$ level.

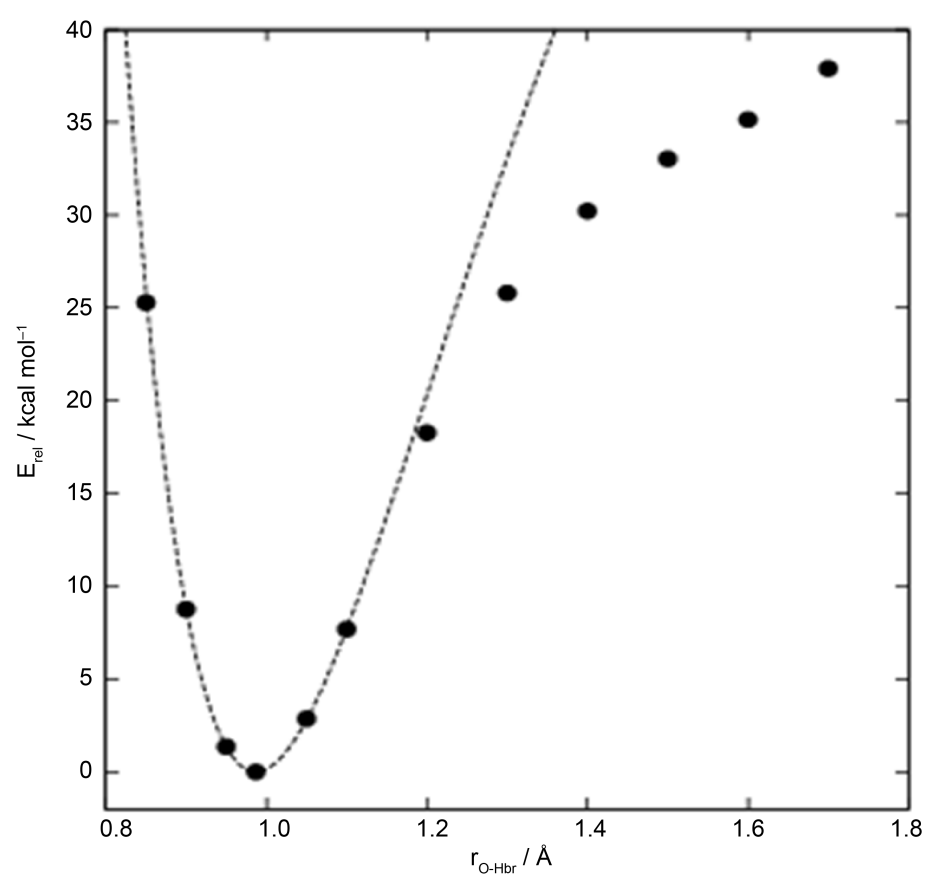

Fig. S6.1. PBE0-D3/Wachters / 6-31G ${ }^{*(*)}$ energy as a function of the two O-Hbr distances (kept equal, all other parameters optimised); dotted line: fit of a Morse potential to the five points below $10 \mathrm{kcal} \mathrm{mol}^{-1}$.

The zero-point averaged structure is still planar. To probe to what extent out-ofplane twists could affect the pNMR shifts a relaxed energy scan was carried out along a suitable reaction coordinate and computed the shieldings for these twisted structures. The chosen coordinate comprised the Oa-C1-C1'-Oa' and $\mathrm{Nb}-\mathrm{C} 1-\mathrm{Cl}^{\prime}-\mathrm{Nb}^{\prime}$ dihedral angles, which were fixed to the same value $\theta$ (see Fig. S6.2(a) for the numbering scheme used here). In addition, the $\mathrm{C} 1-\mathrm{Cu}-\mathrm{C}^{\prime}$ angle was kept fixed at $180^{\circ}$ to ensure a smooth transition between the planar and a pseudo-tetrahedral coordination geometry about $\mathrm{Cu}$; all other parameters were optimised at the PBE0-D3/Wachters/6-31G ${ }^{*(*)}$ level. As 
expected for a $\mathrm{d}^{9}$ complex from the first transition row, the pseudo-tetrahedral structure with $\theta=90^{\circ}$ is very high in energy $\left(32.3 \mathrm{kcal} \mathrm{mol}^{-1}\right.$ above the minimum at $\left.\theta=180^{\circ}\right)$, but quite noticeable distortions up to $\theta=155^{\circ}$ cost less than $4 \mathrm{kcal} \mathrm{mol}^{-1}$ (see Fig. S6.2(b)).
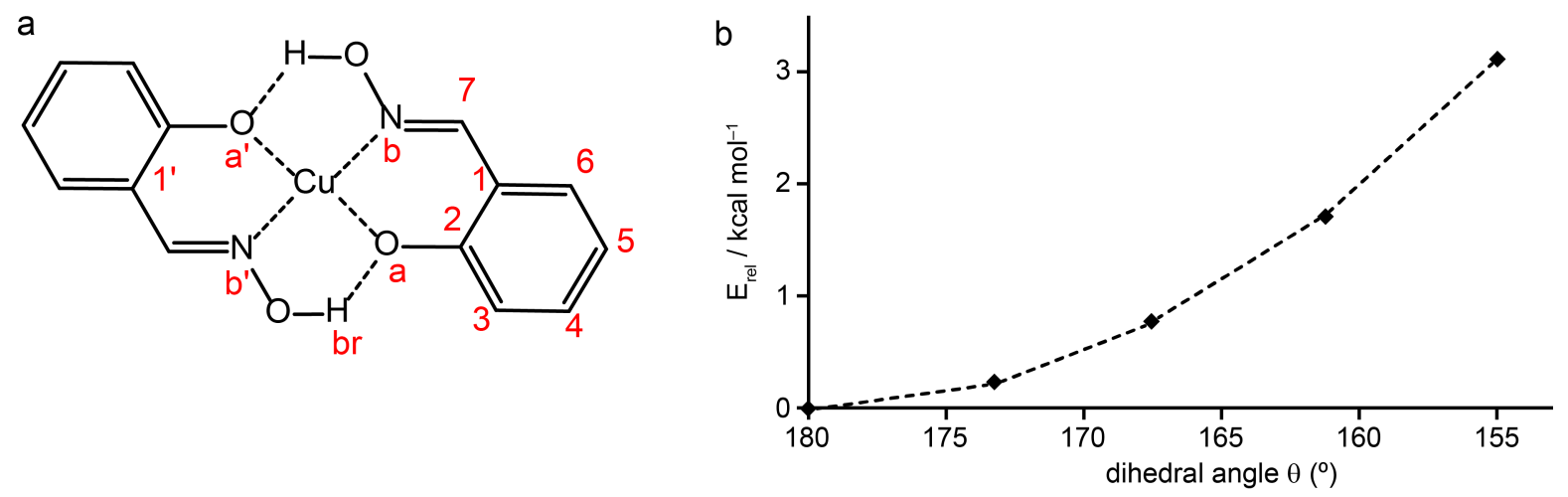

Fig. S6.2. (a) Numbering scheme for 1, including for the $\mathrm{N}$ and $\mathrm{O}$ atoms. (b) PBE0D3/Wachters / 6-31G ${ }^{*(*)}$ energy as a function of the two Oa-C1-C1'-Oa' and $\mathrm{Nb}-\mathrm{C} 1-\mathrm{C} 1^{\prime}-\mathrm{Nb}^{\prime}$ dihedral angles.

The pNMR chemical shifts computed for these twisted structures are given in Table S6.3 and the resulting schematic NMR spectra as a function of the twist are plotted in Fig. S6.3. There are noticeable shifts of some signals with increasing twist, notably for Hbr, C7 and C2. In many cases, the trends are opposite to those of the full zero-point vibrational averaging given in Table S6.1 (e.g., Hbr is predicted to be shielded by full vibrational averaging, ${ }^{\mathrm{S} 31}$ but deshielded by out-of-plane twists; but vice versa for H7). Full appraisal would require a dynamical study (preferably including nuclear dynamics), ${ }^{532}$ which is beyond the scope of the present paper. 
Table S6.3. Computed pNMR chemical shifts (in ppm relative to TMS) for complex 1 as a function of dihedral twist angle $\theta$.

\begin{tabular}{cccccc}
\hline Species & \multicolumn{5}{c}{$\theta\left(^{\circ}\right)$} \\
& 180.00 & 173.75 & 167.50 & 161.25 & 155.00 \\
\hline H3 & -6.8 & -7.1 & -7.2 & -7.7 & -8.4 \\
H4 & 35.0 & 35.0 & 34.8 & 34.6 & 34.3 \\
H5 & 6.5 & 6.4 & 6.0 & 5.4 & 4.5 \\
H6 & 13.4 & 13.4 & 13.6 & 13.9 & 14.5 \\
H7 & 306.6 & 305.1 & 303.0 & 299.0 & 293.7 \\
Hbr & 31.7 & 34.2 & 36.9 & 50.2 & 61.5 \\
C1 & 132.2 & 132.1 & 132.8 & 133.0 & 135.1 \\
C2 & 79.4 & 73.1 & 49.9 & 9.2 & -39.9 \\
C3 & 1166.5 & 1164.1 & 1163.4 & 1155.4 & 1147.1 \\
C4 & 235.2 & 234.0 & 232.0 & 227.1 & 220.7 \\
C5 & 144.7 & 145.3 & 146.6 & 149.7 & 154.2 \\
C6 & 108.7 & 107.9 & 105.6 & 100.9 & 94.4 \\
C7 & 931.5 & 919.3 & 896.8 & 851.2 & 797.5 \\
\hline
\end{tabular}

a. PBE0-1/3/IGLO-II level.

a

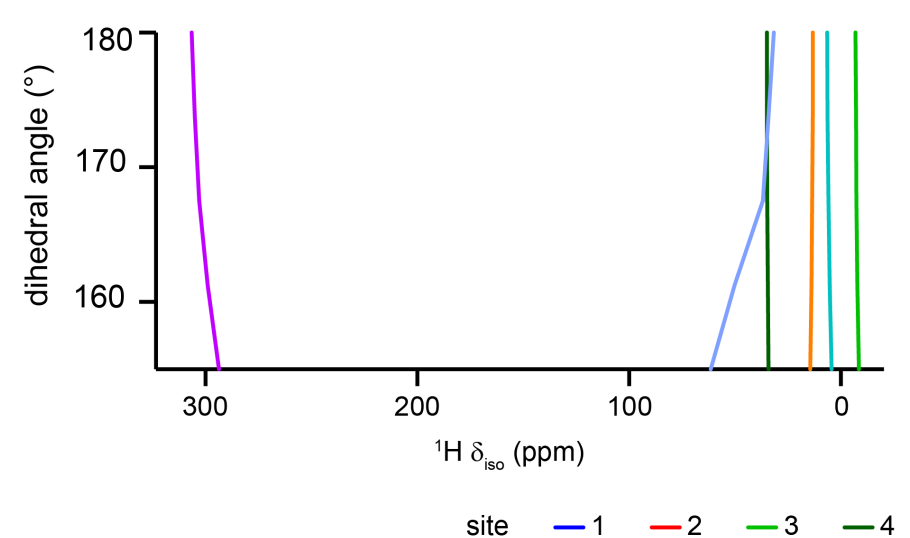

$\mathrm{b}$

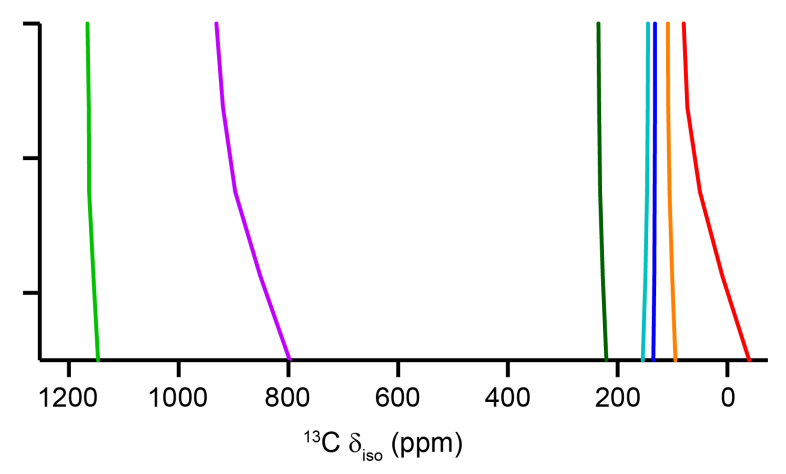

$\begin{array}{llll}-5 & -6 & -7 & -\mathrm{br}\end{array}$

Fig. S6.3. Plots of computed (a) ${ }^{1} \mathrm{H}$ and (b) ${ }^{13} \mathrm{C}$ isotropic shifts (at $298.15 \mathrm{~K}$ ) as a function of the dihedral twist angle $\theta$. For numerical values, see Table S6.3. 


\section{S7. References}

S1. M. Bühl, S. E. Ashbrook, D. M. Dawson, R. A. Doyle, P. Hrobárik, M. Kaupp and I. A. Smellie, Chem. Eur. J., 2016, 22, 15328.

S2. N. Otto and T. Opatz, Beilstein J. Org. Chem., 2012 , 8, 1105.

S3. C. E. Coulthard, J. Marshall and F. L. Pyman, J. Chem. Soc., 1930, 280.

S4. H. A. Torrey and C. M. Brewster, J. Am. Chem. Soc., 1913, 35, 426.

S5 L. Rupp, Arch. Pharm., 1915, 253, 34

S6. I. A. Smellie, R. S. Forgan, C. Brodie, J. S. Gavine, L. Harris, D. Houston, A. D. Hoyland, R. P. McCaughan, A. J. Miller, L. Wilson and F. M. Woodhall, J. Chem. Educ., $2016,93,362$.

S7. D. Stepniak-Biniakiewicz, Pol. J. Chem., 1980, 54, 7.

S8. Patent WO2004/67518 A1,Bayer Cropscience Aktiengesellschaft, 2004.

S9. N. Gigant, E. Claveau, P. Bouyssou and I. Gillaizeau, Org. Lett., 2012, 14, 844.

S10. M. Dolai, T. Mistri, S. Biswas, G. Rogez and M. Ali, ChemPlusChem, 2014, 79, 1649.

S11. K. N. Lazarou, A. K. Boudalis, V. Psycharis and C. P. Raptopoulou, Inorg. Chim. Acta, 2011, 370, 50.

S12. F. M. Mack, MChem Thesis, University of St Andrews, 2017.

S13. Gaussian 09, Revision B.01, M. J. Frisch, G. W. Trucks, H. B. Schlegel, G. E. Scuseria, M. A. Robb, J. R. Cheeseman, G. Scalmani, V. Barone, B. Mennucci, G. A. Petersson, H. Nakatsuji, M. Caricato, X. Li, H. P. Hratchian, A. F. Izmaylov, J. Bloino, G. Zheng, J. L. Sonnenberg, M. Hada, M. Ehara, K. Toyota, R. Fukuda, J. Hasegawa, M. Ishida, T. Nakajima, Y. Honda, O. Kitao, H. Nakai, T. Vreven, J. A. Montgomery, Jr., J. E. Peralta, F. Ogliaro, M. Bearpark, J. J. Heyd, E. Brothers, K. N. Kudin, V. N. Staroverov, T. Keith, R. Kobayashi, J. Normand, K. Raghavachari, A. Rendell, J. C. Burant, S. S. Iyengar, J. Tomasi, M. Cossi, N. Rega, J. M. Millam, M. Klene, J. E. Knox, J. B. Cross, V. Bakken, C. Adamo, J. Jaramillo, R. Gomperts, R. E. Stratmann, O. Yazyev, A. J. Austin, R. Cammi, C. Pomelli, J. W. Ochterski, R. L. Martin, K. Morokuma, V. G. Zakrzewski, G. A. Voth, P. Salvador, J. J. Dannenberg, S. Dapprich, A. D. Daniels, O. Farkas, J. B. Foresman, J. V. Ortiz, J. Cioslowski and D. J. Fox, Gaussian, Inc., Wallingford CT, 2013. 
S14. J. P. Perdew, In Electronic Structure of Solids, Ziesche, P.; Eischrig, H. Eds.: Akademie Verlag: Berlin (1991).

S15. J. P. Perdew and Y. Wang, Phys. Rev. B 1992, 45, 13244.

S16. J. P. Perdew, M. Ernzerhof and K. Burke, J. Phys. Chem. 1996, 105, 9982.

S17. C. Adamo and V. Barone, J. Chem. Phys. 1999, 110, 6158.

S18 S. Grimme, J. Antony, S. Ehrlich and H. Krieg, J. Chem. Phys. 2010, 132, 154104.

S19. A. D. Becke and E. R. Johnson, J. Chem. Phys. 2005, 122, 154104.

S20. E. R. Johnson and A. D. Becke, J. Chem. Phys. 2006, 124, 174104.

S21. A. J. H. Wachters, J. Chem. Phys. 1970, 52, 1033.

S22. P. J. Hay, J. Chem. Phys. 1977, 66, 4377.

S23. C. A. Guido, E. Bremond, C. Adamo and P. Cortona, J. Chem. Phys. 2001, 138, 201104.

S24. M. Munzarová and M. Kaupp, J. Phys. Chem. A 1999, 103, 9966.

S25. W. Kutzelnigg, U. Fleischer and M. Schindler, In: NMR Basic Principles and Progress Vol. 23, Springer-Verlag: Berlin, 1990, p. 165.

S26. Orca, Version 3.0.3: (a) F. Neese, WIREs Comp. Mol. Sci 2012, 2, 73; (b) https: / / orcaforum.cec.mpg.de (accessed 20 May 2016).

S27. P. Hrobarik, R. Reviakine, A. V. Arbuznikov, O. L. Malkina, V. G. Malkin, F. Koehler and M. Kaupp. J. Chem. Phys. 2007, 126, 024107.

S28. J. Skibsted and H. J. Jakobsen, J. Phys. Chem. A, 1999, 103, 7958-7971.

S29. (a) V. Barone J. Chem. Phys. 2004, 120, 3059. (b) V. Barone, J. Chem. Phys. 2005, 122, 014108. See also: (c) K. Ruud, P.-O. Åstrand and P. R. Taylor, J. Chem. Phys. 2000, 112, 2668. (d) K. Ruud, P.-O. Åstrand and P. R. Taylor, J. Am. Chem. Soc. 2000, 123, 4826. (e) T. Ruden, O. B. Lutnæss and T. Helgaker, J. Chem. Phys. 2003, 118, 9572.

S30. See e.g., (a) M. Bühl, C. Reimann, D. A. Pantazis, T. Bredow and F. Neese, J. Chem. Theory Comput. 2008, 4, 1449. (b) S. Grigoleit and M. Bühl, Chem. Eur. J., 2004, 10, 5541.

S31. Note that full vibrational averaging would require expansion of the nuclear shielding surface about the effective $\left(\mathrm{r}_{\mathrm{g}}{ }^{0}\right)$ structure and perturbative inclusion of the resulting corrections to the effective shielding $\left(\sigma_{\text {eff }}\right)$ at the $r_{g}{ }^{0}$ structure (through the second derivative of the magnetic shielding surface, $c f$. references S29(d,e)); because this procedure is rather costly and usually produces only minor corrections to $\sigma_{\text {eff }}$ 
(especially for transition metal complexes, see: M. Bühl, P. Imhof and M. Repisky, ChemPhysChem. 2004, 5, 414) it was not implemented here.

S32. For a path integral molecular dynamics study of ${ }^{13} \mathrm{C} \delta_{\text {iso }}$ in diamagnetic molecular organic solids see: M. Dracinsky and P. Hodgkinson, Chem. Eur. J. 2014, 20, 2201. 